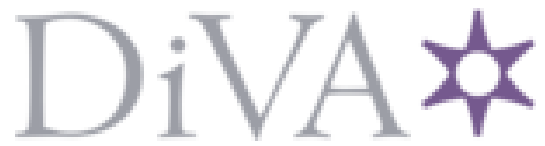

http://www.diva-portal.org

\title{
Postprint
}

This is the accepted version of a paper published in . This paper has been peer-reviewed but does not include the final publisher proof-corrections or journal pagination.

Citation for the original published paper (version of record):

Mestres, G., Perez, R A., d'Elía, N., Barbe, L. (2019)

Advantages of microfluidic systems for studying cell-biomaterial interactions-focus on bone regeneration applications

Biomedical Physics \& Engineering Express, 5(3): 032001

https://doi.org/10.1088/2057-1976/ab1033

Access to the published version may require subscription.

N.B. When citing this work, cite the original published paper.

Permanent link to this version:

http://urn.kb.se/resolve?urn=urn:nbn:se:uu:diva-381400 


\section{Advantages of microfluidic systems for studying cell-biomaterial interactions - Focus on bone regeneration applications}

To cite this article before publication: Gemma Mestres et al 2019 Biomed. Phys. Eng. Express in press https://doi.org/10.1088/2057-1976/ab1033

\section{Manuscript version: Accepted Manuscript}

Accepted Manuscript is "the version of the article accepted for publication including all changes made as a result of the peer review process, and which may also include the addition to the article by IOP Publishing of a header, an article ID, a cover sheet and/or an 'Accepted Manuscript' watermark, but excluding any other editing, typesetting or other changes made by IOP Publishing and/or its licensors"

This Accepted Manuscript is @ 2018 IOP Publishing Ltd.

During the embargo period (the 12 month period from the publication of the Version of Record of this article), the Accepted Manuscript is fully protected by copyright and cannot be reused or reposted elsewhere.

As the Version of Record of this article is going to be / has been published on a subscription basis, this Accepted Manuscript is available for reuse under a CC BY-NC-ND 3.0 licence after the 12 month embargo period.

After the embargo period, everyone is permitted to use copy and redistribute this article for non-commercial purposes only, provided that they adhere to all the terms of the licence https://creativecommons.org/licences/by-nc-nd/3.0

Although reasonable endeavours have been taken to obtain all necessary permissions from third parties to include their copyrighted content within this article, their full citation and copyright line may not be present in this Accepted Manuscript version. Before using any content from this article, please refer to the Version of Record on IOPscience once published for full citation and copyright details, as permissions will likely be required. All third party content is fully copyright protected, unless specifically stated otherwise in the figure caption in the Version of Record.

View the article online for updates and enhancements. 


\title{
Advantages of microfluidic systems for studying cell-
} biomaterial interactions - Focus on bone regeneration applications

\author{
Gemma Mestres ${ }^{1 *}$, Roman A. Perez ${ }^{2}$, Noelia Laura D’Elía ${ }^{3}$, Laurent Barbe ${ }^{1}$ \\ ${ }^{1}$ Engineering Sciences Department, Science for Life Laboratory, Uppsala University, \\ Uppsala, Sweden \\ ${ }^{2}$ Bioengineering Institute of Technology, Universitat Internacional de Catalunya, \\ Barcelona, Spain \\ ${ }^{3}$ Department of Chemistry, Universidad Nacional del Sur, INQUISUR-CONICET, \\ Bahía Blanca, Argentina \\ * Corresponding author: Gemma Mestres \\ Postal Address: Microsystems Technology Division, Engineering Sciences Department, Uppsala \\ University, Box 534, 75121 Uppsala, Sweden \\ E-mail: gemma.mestres@angstrom.uu.se
}

\begin{abstract}
The poor correlation between in vitro and in vivo studies emphasises the lack of a reliable methodology for testing the biological properties of biomaterials in the bone tissue regeneration field. Moreover, the success of clinical trials is not guaranteed even with promising results in vivo. Therefore, there is a need for a more physiologically relevant in vitro model to test the biological properties of biomaterials.

Microfluidics, which is a field concerning the manipulation and control of liquids at the submillimetre scale, can use channel geometry, cell confinement and fluid flow to recreate a physiological-like environment. This technology has already proven to be a powerful tool in studying the biological response of cells in defined environments, since chemical and mechanical inputs as well as cross-talk between cells can be finely controlled. Moving a step further in complexity, biomaterials can be integrated into microfluidic systems to evaluate biomaterial-cell interactions. The biomaterialmicrofluidics combination has the potential to produce more physiologically relevant models to better screen the biological interactions established between biomaterials and cells.

This review is divided into two main sections. First, several possible cell-based assays for bone regeneration studies in microfluidic systems are discussed. Second, and the ultimate goal of the review, is to discuss how the gap between in vitro and in vivo studies can be shortened by bridging the biomaterials and microfluidics fields.
\end{abstract}

\section{Keywords}

Bone regeneration $\bullet$ Biomaterials $\bullet$ Cell cultures $\bullet$ In vitro $\bullet$ Microfluidics $\bullet$ Microsystems technology 


\section{Contents}

1. Introduction 3

2. Standard in vitro methods to evaluate biological properties of biomaterials ....................4

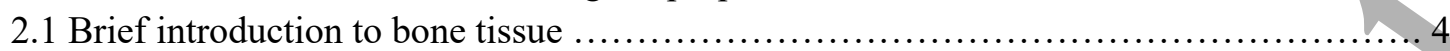

2.2 Two-dimensional (2D) versus three dimensional (3D) cultures .....................4

2.3. Dynamic cultures

3. Microfluidics for cell-based assays for bone tissue regeneration

3.1. Real-time monitoring

3.2. Spatial configuration for cell culturing

3.3 Mechanotransduction

3.4 Chemicals and gradients

3.5 Co-culture

3.6 Combination of designs

4. Microfluidics for evaluating the biological properties of biomaterials for bone tissue regeneration 21

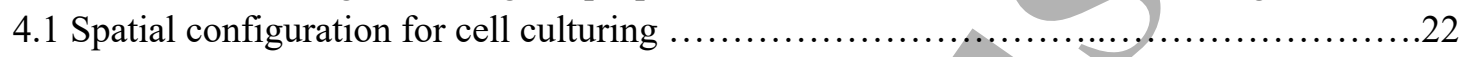

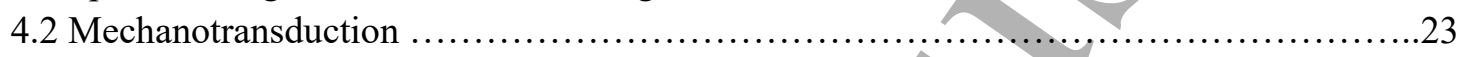

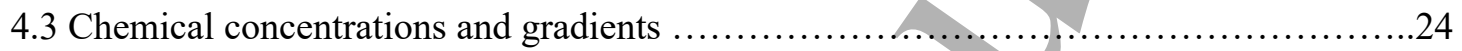

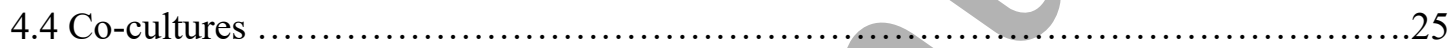

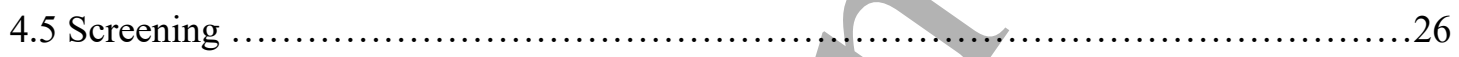

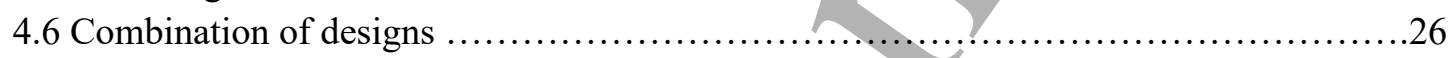

5. Conclusions and future perspectives: bridging the gap between biomaterials and microfluidics ...27

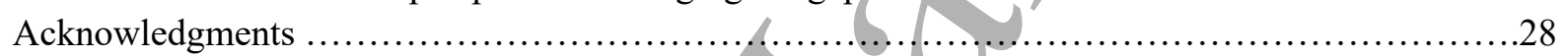

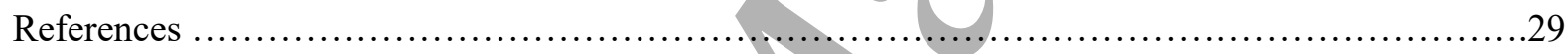

\section{Abbreviations}

2D: Two-dimensional

3D: Three-dimensional

ALP: Alkaline Phosphatase

BMP-2: Bone Morphogenetic Protein 2

CFU: Colony-forming units

ECM: Extracellular Matrix

MSCs: Mesenchymal Stem Cells

PDMS: Polydimethylsiloxane

PEG: Poly(Ethylene Glycol) 


\section{Introduction}

The use of biomaterials to regenerate damaged tissues has been studied for several decades. A gradual change of paradigm has however occurred, evolving from biomaterials that would simply mechanically substitute a damaged tissue to biomaterials that would interact with the host environment and evolve according to its biological requirements. This evolution of biomaterials has allowed researchers to gain a deeper understanding of a host tissue such as bone. In turn this has led to the development of materials that replicate to a higher extent the physico-chemical, architecture and biological characteristics of bone tissue. For instance, the materials' elasticity/stiffness influences the internal cytoskeletal tension of cells [1]; wettability and material charge affect protein adsorption and denaturalization [2]; macroporosity determines cell migration; and nano/microporosity dictates protein adsorption [3]. Consequently, there is a vast amount of variability in biomaterials that can be tuned to mimic native tissues and determine cell fate. The great implications in the material design and the need to mimic the native tissues has allowed biomaterials science to be redefined, moving from an engineering design to a more complex one that includes a biological approach, in which multidisciplinary teams are needed.

Cell cultures are performed as a screening step to select those materials that may have potential clinical applications. This is done by testing the materials with cells (in vitro assays) to determine cell viability, proliferation (growth rate), differentiation (path into which mesenchymal stem cells, MSCs, differentiate), inflammatory response, etc. The chosen materials then undergo animal studies (in vivo assays) that may ultimately provide fruitful information in validating their role in a clinical scenario. However, a rather low correlation between in vitro cell studies and in vivo studies [4] has been observed. Hence, biomaterials selected in vitro might cause a negative material-animal interaction when implanted in animals, thus several animals being sacrificed in vain. On the other hand, biomaterials that had been disregarded due to their negative cell-material interaction could actually have a potential clinical application but are not studied any further due to negative in vitro results. This misleading response of some in vitro cell cultures may increase the time for new materials to reach the market, with a higher cost, unnecessary sacrifice of animals and without providing any conclusive result. The main reason for the poor match between in vitro cell cultures and in vivo animal models arises from the complexity of living organisms, which are built up of multiple types of cells that secrete signalling molecules, together with a specific body flux that is able to establish a balance in the body between nutrients and waste. These conditions are very vaguely mimicked in conventional in vitro cultures and for this reason new technological tools to more reliably evaluate the biomaterial-cell interactions are needed.

Microfluidics can be an interesting tool to closely mimic in vivo conditions in cell culture models. This Science deals with the manipulation and fine control of liquids at the submillimeter scale, where flow tends to have a laminar behaviour rather than a turbulent one [5]. Microfluidic systems permit to culture cells in a confined way as it occurs in the body [6-9], preserving cells phenotype [10]. In fact, reaching a tight control of the space, time and physico-chemical conditions [11] and decreasing the volume-per-cell ratios (intercellular signalling is amplified) [8] would not be possible otherwise. Therefore, microfluidic systems can be used as a platform for developing highly relevant physiological models that allow answering some new biological questions [12-14]. Since the flow applied in such devices can be modulated to mimic the physiological one, this technology has already been moved to a more complex stage by recapitulating the microarchitecture and function of some organs such as lung [15], brain [16-18], heart [19], intestines [20], etc. Moreover, it is foreseen that a "body-on-a-chip" could be created to evaluate the cross-talk between cells present in different organs [13,21], which would be of high interest for pharmaceutical companies [22]. Hence, the use of microfluidics technology is gaining acceptance as a revolutionary tool that has only been recently started to be used in the testing of biomaterials.

Nevertheless, microfluidic systems still present some drawbacks that limit their common use for testing biomaterials in vitro. Due to the use of micron-sized technologies and the need to maintain a 
clean environment with very specific equipment, the availability of microfluidic systems to all researchers is limited [23]. This makes difficult the technology transfer between different research groups [24] as well as getting a general interest from the scientific society. In general, it may also be challenging to make long-term assays [25] due to technical issues, although some long-term experiments have been performed under specific arrangements [26-28]. Finally, the low number of scientific studies using this type of devices turns this technology in a fairly new field and, therefore, the insight is limited [24].

In this review, we will discuss how microfluidic-based devices can actually fill the gap between in vitro and in vivo studies, and we will explain the potential of such technology in bone tissue regeneration applications. This review covers different strategies that have been used to culture osteoblasts and mesenchymal stem cells (MSCs) in microfluidic-based systems for bone regeneration studies and how this technology can also be used to test biomaterials in cell culture.

\section{Standard in vitro methods to evaluate biological properties of biomaterials}

\subsection{Brief introduction to bone tissue}

Bone is a highly hierarchical tissue constituted of organic (mainly collagen) and mineral components (mainly calcium deficient hydroxyapatite). Bone structure accounts for $80 \%$ of bone volume, the remaining $20 \%$ being physiological fluid [29]. Bones adapt in response to the functional demands by remodeling itself to achieve an optimal balance of strength and mass [30,31]. This means that if bone is loaded above the habitual levels, i.e. while exercising, remodeling shifts towards bone formation [32,33]; in the opposite situation, i.e. bedridden, bone resorption occurs [34]. It is believed that bone cells are not directly affected by the mechanical strain, but indirectly due to the pressure applied to the interstitial fluid through the ECM. In turn, the changes caused to the interstitial fluid produce meaningful variations in shear stress, influencing the response of resident osteoblasts and osteocytes $[35,36]$. The physiological shear stress acting on the cell membrane has been estimated to be $0.06-30 \mathrm{dyn} / \mathrm{cm}^{2}[36,37]$.

\subsection{Two-dimensional (2D) versus three dimensional (3D) cultures}

The physiological relevance of in vitro studies can be increased by including a proper biological context (e.g. extracellular matrix, ECM, or co-cultures), mechanical strains, as well as chemical or spatial cues (culturing cells in 3D configuration) [25]. However, it is difficult to mimic the true complexity of the body and therefore simplified in vitro models are often used. Table 1 summarizes the main characteristics of 2D and 3D culture models, most of which apply to both macrometric (standard cultures) and micrometric (microfluidic devices) culture models.

\section{$2 D$ cultures}

2D culture assays are used to evaluate cell-biomaterial interactions by culturing the cells either directly onto the biomaterial surface (direct contact assay) or with a cell culture medium that the biomaterial had been preliminary immersed in (indirect contact assay) [38]. In most cases, these assays are performed in polystyrene-vessels such as well plates or Petri dishes, and cells are cultured in monolayer under static conditions.

Direct contact assays are more complex when evaluating bioactive materials, which interact with the culture medium by either releasing ions/compounds and/or adsorbing ions or proteins. Bioactive glasses or microporous calcium phosphates are examples of well-known bioactive materials $[3,38]$. For such materials, the cells will not only be influenced by the material superficial properties but also by the compounds present in the cell culture medium. Therefore, performing both a direct and indirect contact assay might be helpful to elucidate the influence of the compounds in solution from that 
of the material superficial properties [39]. Another methodology to counteract the modification of the medium by bioactive materials is to minimize the surface-to-volume ratio in the culture, i.e. using a small biomaterial in a proportionally big amount of cell culture medium [40].

Direct methods have been widely used to study the key role of biomaterials' surface porosity and roughness in the osteogenic process [3]. Nano- and micro- topographies have been shown to enhance the growth and differentiation of osteoblasts [41]. Moreover, in order to improve attachment and differentiation of osteogenic cells, biomaterials can be pre-coated with RGD-containing compounds (e.g. gelatin, collagen or Matrigel solution), or with osteogenic growth factors [42].

The main advantage of 2D cultures is that they are simple and easy to implement in any cell culture laboratory. Moreover, they are suitable for testing both the cytotoxicity of a new biomaterial, as well as the cell response to some surface material properties, such as chemistry or roughness. The main drawback of $2 \mathrm{D}$ systems is that cell phenotypes may be modified due to the lack of $3 \mathrm{D}$ spatial cues $[43,44]$.

\section{$3 D$ cultures}

3D cultures are used to evaluate the biological properties of porous bulk materials. Bioreactors (described further in the "Dynamic culture" section) are commonly used to ensure perfusion of cell culture media throughout the porous material. Due to the increased level of complexity of 3D models, spatial and temporal gradients of biochemical signals might be produced [45].

The cells forming our tissues and organs grow in a 3D conformation. Therefore, cells provide information closer to in vivo conditions when cultured in this spatial configuration $[11,43]$ and, in fact, there are some biological processes that can only occur in 3D microenvironments [11].

Since 3D cultures are usually performed in dynamic conditions, we have further developed this topic in the "3D dynamic cultures" section.

Table 1. Main characteristics of in vitro cell cultures in 2D and 3D configurations (applies to both macrometric and micrometric culture models).

\begin{tabular}{l|ll}
\hline \multicolumn{1}{c}{ 2D culture } & \multicolumn{3}{c}{ 3D culture } \\
\hline Simplicity & $\begin{array}{l}\text { A more biologically relevant model [43]; some } \\
\text { biological processes can only occur at 3D } \\
\text { microenvironment [11] }\end{array}$ \\
\hline $\begin{array}{l}\text { Appropriate for adhesive cells [46] } \\
\text { Can be used to determine the influence of flow } \\
\text { regimes (e.g. shear stress level, steady vs. } \\
\text { oscillatory, duration of flow, insertion of resting } \\
\text { period) and chemical cues [6] }\end{array}$ & $\begin{array}{l}\text { Permits cross-talk between different } \\
\text { populations [45] }\end{array}$ & \\
\hline
\end{tabular}

\section{DRAWBACKS OR CHALLENGES TO BE CONSIDERED}

Cells may lose their phenotypes/when cultured in Cell viability can be compromised if lacking an $2 \mathrm{D}$ environments $[43,44]$ efficient transport of nutrients and oxygen, and waste removal [11]

Plastic is the main mechanical support of cells, Difficult to produce a homogeneous distribution which has a different stiffness than ECM [47] of cells in a porous material [10] 


\subsection{Dynamic cultures}

A dynamic culture usually implies that the culture media is continuously moving, either along a biomaterial surface (2D dynamic cultures) or perfused throughout a porous biomaterial (3D dynamic cultures). For this purpose, bioreactors, which are automatic devices that provide an acceptable degree of reproducibility and control of the flow conditions, are commonly used [48].

From the beginning of tissue engineering, researchers have been seeking new methodologies to mimic the physiological conditions of bone when culturing cells in vitro. Bioreactors have permitted to incorporate physiological stimuli to the cell cultures [49]. Another benefit of dynamic systems is the continuous perfusion of nutrients and oxygen, and the removal of waste $[10,46,50]$. This continuous exchange has also been proved to facilitate remodelling and vascularization [51]. Media perfusion along/throughout a biomaterial causes mechanotransduction [27,35,52,53], which may reproduce physiological conditions. In particular, shear stress may be needed for tissue development and bone formation, enhancing MSCs to mature toward bone-depositing osteoblasts [51] (see "3D dynamic cultures).

Nevertheless, dynamic systems also present some problems. Having a constant flow could impede the local accumulation of secreted factors [25]. Dynamic systems are more challenging to operate and control than static ones $[23,46]$. Furthermore, the use of non-laminar fluxes that may occur could induce substrate damage and be harmful for cells.

\section{$2 D$ dynamic cultures}

2D dynamic cultures may intrinsically stimulate the cells growing on the biomaterial surface with fluid perfusion through shear stress. Such a bioreactor may consist of one or multiple 2D plate flow chambers, which inlet (fresh medium flows in) and outlet (outcoming medium is directed to a waste container or recirculated) are connected to a pump [54]. These 2D studies allow controlling the flow rate and can provide information on how MSCs and osteoblasts respond to shear stress [54].

\section{D dynamic cultures}

In bone tissue engineering, mainly three types of 3D bioreactors are used: spinner flasks, rotating wall vessels, and perfusion systems. While the two former ones are effective at creating a homogenous media solution on the exterior of a biomaterial, perfusion systems can efficiently perfuse media throughout a scaffold. In particular, perfusion bioreactors enhance nutrient transport and oxygen along the scaffold, while waste products are removed. Moreover, perfusion bioreactors also expose cells to fluid shear stresses [55]. It is however more difficult to elucidate the effect of only shear stress in the 3D dynamic systems compared with 2D ones.

Cell behaviour on static and dynamic conditions has been compared. Bartnikowski et al. proved that while cells under static conditions showed a similar response in 3D scaffolds with different architectures, the osteogenic differentiation when culturing cells under perfusion was linked to the scaffold's architecture [56].

Dynamic cultures might additionally be designed to mechanically stimulate (e.g. compression, tension or shear stress) the cells in the scaffold, therefore allowing mechanotransduction studies [48]. The importance of mechanical stimuli for bone regeneration studies has been repetitively proved. Studies using different types of bioreactors confirmed that the mineralization of the ECM was accelerated (or only achieved) when the scaffold was cultured under the presence of a local mechanical strain (in comparison to static-cultured conditions) [57-59]. In some cases, however it was difficult to identify if this was due to the loading itself or to the higher flow exchange, which improved nutrient supply and removal of waste products [57]. 
Even though a dynamic system increases the complexity of a study, it might be required to evaluate the cell behaviour inside a 3D material in physiological-like conditions. For further insight into bioreactors, readers are directed to reviews that cover several types of bioreactor designs [60] and perfusion bioreactors [61].

\section{Microfluidics for cell-based assays for bone tissue regeneration}

Microfluidic technology may provide the opportunity to recreate a physiological-like environment for biomaterials. Such systems allow a fine control of the environment where mechanical inputs (mechanical load and shear stress) and cross-talk between cells can be included. A simple microfluidic system is schematically shown in Figure 1. There are several alternatives to design a microfluidic device, mainly dependant on the materials used and the microchannel dimensions, which have to be adapted to the needs of each specific study.

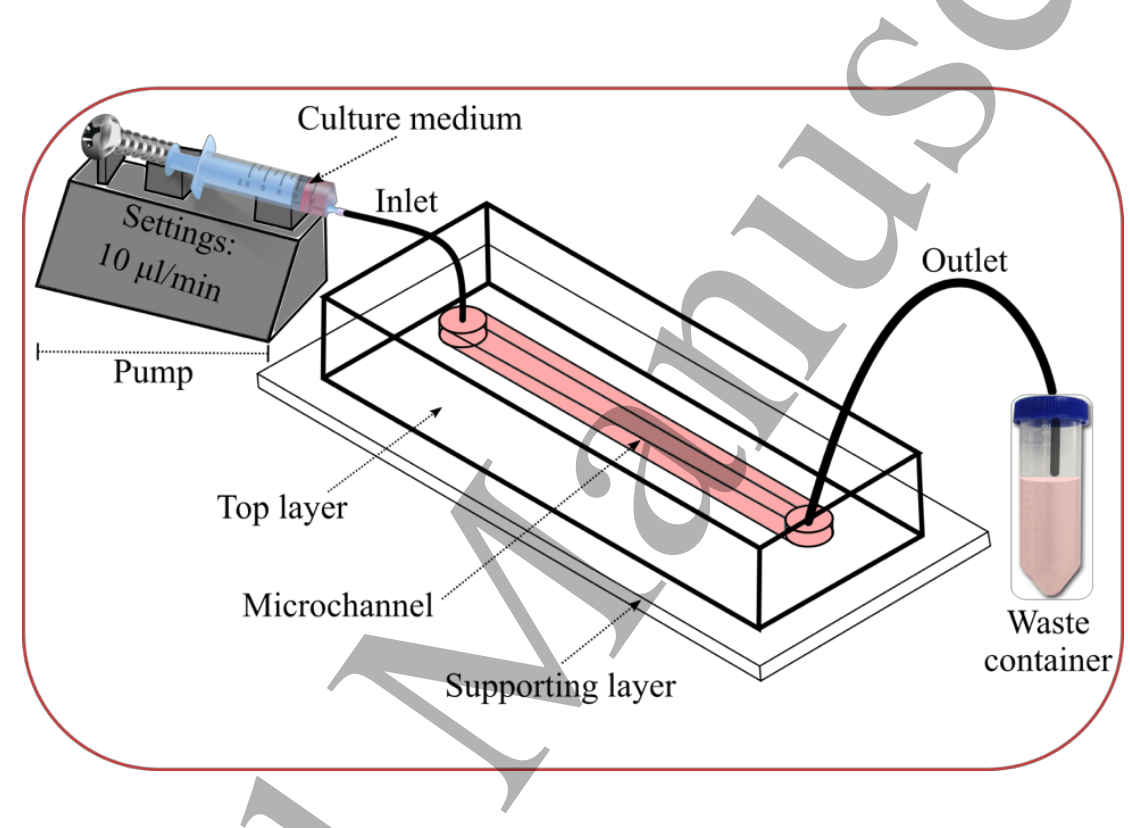

Figure 1. Schematic model of a microfluidic cell culture system constituted by a straight microchannel. In this device, cells are seeded into a microchannel that consists of a flat transparent support layer (e.g. glass), and a transparent and gas-permeable top layer (e.g. polydimethylsiloxane, PDMS) containing a defined channel.

A pump perfuses culture medium through the inlet and waste medium coming from the outlet is collected.

The common methods to culture cells have been described in section 2 . Table 2 briefly summarizes the main advantages and disadvantages of using microfluidics for cell culturing in comparison to conventional macrometric methods. 
Table 2. Advantages and drawbacks of culturing cells in micrometric sizes.

\begin{tabular}{|c|}
\hline ADVANTAGES \\
\hline $\begin{array}{l}\text { Cell phenotype is more likely to be preserved [10] since sizes and cell confinement are col } \\
\text { an in vivo-like microenvironment }[6,7,46]\end{array}$ \\
\hline $\begin{array}{l}\text { Tight spatial and temporal control of the cells }[8,11,45,62] \text { and environmental cues (e.g. media, air : } \\
\text { temperature) }[6,10,11,45] \text {, which may allow reproduction of the physiological conditions }[23]\end{array}$ \\
\hline $\begin{array}{l}\text { Possible to generate precise concentration gradients, localized in space and time, thanl } \\
\text { flow }[11,63-66]\end{array}$ \\
\hline $\begin{array}{l}\text { directly streamed to other cells in real-time, } \\
\text { es [45] }\end{array}$ \\
\hline $\begin{array}{l}\text { Parallel systems permit large-scale automation, combinatorial studies }[6,11,67,68] \text { and } r \\
\text { significant statistical differences }[45]\end{array}$ \\
\hline $\begin{array}{l}\text { Reduced amount of reagents and cells needed }[6,11,62] \text {, making the study more cost-effective and } \\
\text { ethical (e.g. the use of some animal-source reagents is minimized) }\end{array}$ \\
\hline
\end{tabular}

High surface area-to-volume ratios, leading to a higher concentration of cytokines, faster nutrient depletion, and waste accumulation. This may also increase cellular sensitivity to minor fluctuations $[8,24]$

Experienced researchers, usually with a microfabrication background [23], and expensive microfabrication equipment are needed [46]

Might not be robust enough to permit shipment [23], thus hindering the knowledge transfer into other laboratories [24]

Long-term assays are challenging [25]

Microfluidic systems are considered to be a powerful tool in obtaining the biological response of cells in defined environments. While our ultimate goal is to address how the biomaterials can benefit from the use of microfluidics, initially we aim at describing how these microfluidic devices have addressed other biological issues in the field of bone tissue regeneration. This section describes several designs used to perform a variety of cell-on-chip assays: a) real-time monitoring; b) spatial configuration of cell culturing, i.e. 2D and 3D culture, c) mechanotransduction, d) chemicals and chemical gradients, e) co-culture, and f) combination of designs (Figure 2). 


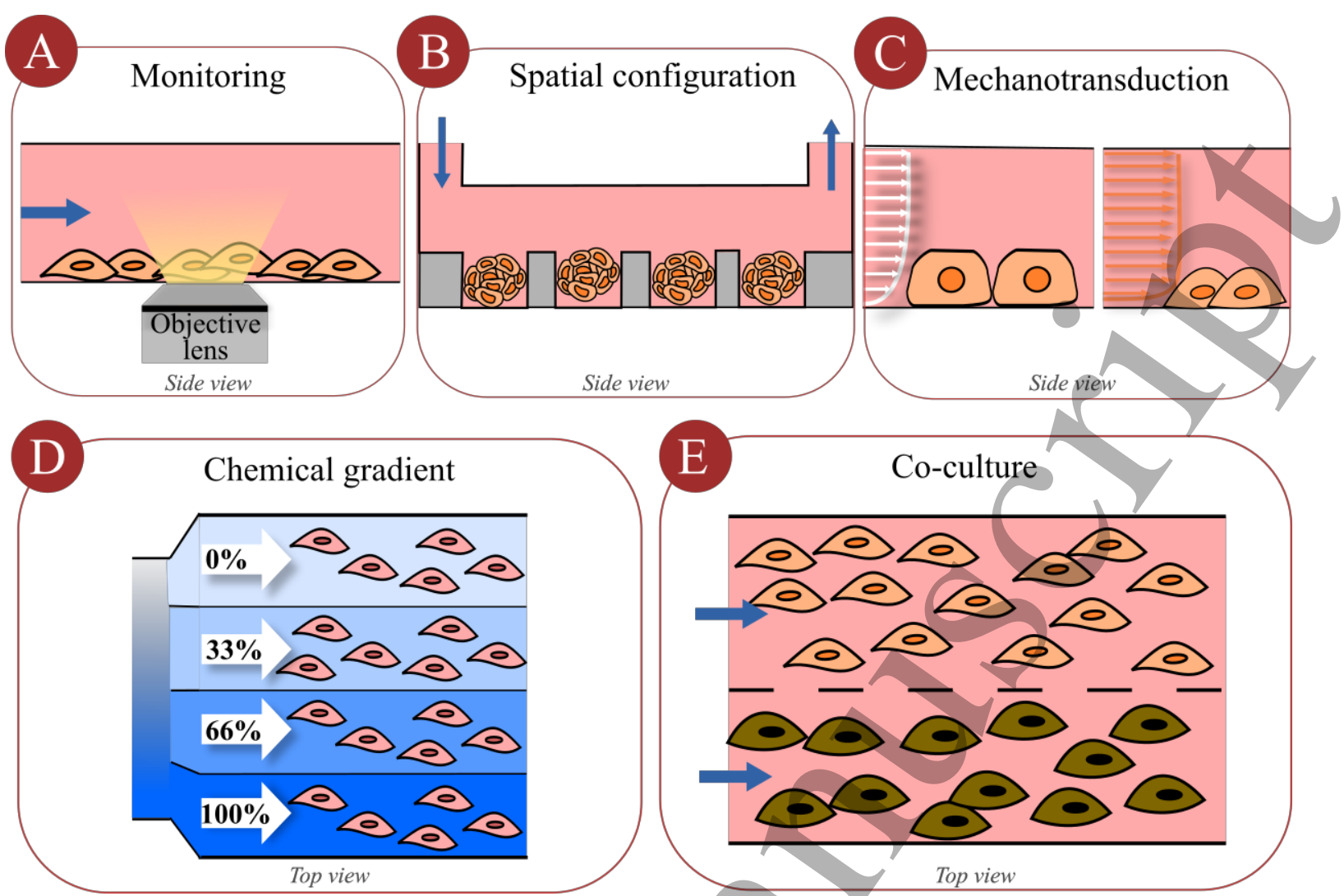

Figure 2. Schematic of possible cells-on-chip design, including: (a) real-time monitoring; (b) spatial configuration for cell culturing; (c), mechanotransduction, (d) chemical gradient, and (e) co-culture. Dashed lines represent semipermeable membranes or pillars.

\subsection{Real-time monitoring}

Microfluidic devices allow for a well-controlled microenvironment, which is favourable for cell growth, and permits their continuous imaging (Figure 2a) and/or monitoring of specific chemical cues [7,46,69,70]. Environmental parameters such as oxygen and $\mathrm{pH}$ have also been monitored in real-time: $\mathrm{pH}$ by light absorption of a medium containing phenol red, and oxygen by the quenching degree of an oxygen-sensitive fluorophore [71]. Such a system allows for continued measurement, reduces the measuring time and its miniaturization simplifies handling.

A more advanced 2D microfluidic system for imaging cells under hypoxia conditions in realtime was developed by Harink et al. The novelty of this work was that the chip could be placed in a standalone holder that allowed control of the cells' physical conditions (temperature and oxygen) while simultaneously allowing real-time imaging [72].

\subsection{Spatial configuration for cell culturing}

Microfluidic devices may be conceived for culturing cells and herein evaluating their biological behaviour in $2 \mathrm{D}$ and $3 \mathrm{D}$ geometries.

Depending on the aim of the study, a 2D configuration may provide fruitful information despite being a simpler system. For instance, a 2D configuration model is appropriate for culturing adhesive cells under different flow regimes or shear stress $[6,10]$. The three main advantages of $2 \mathrm{D}$ models are that they are simple to manufacture and manipulate, cells easily attach on the channel, and cell monitoring is straightforward to achieve [6,46]. Nevertheless, cells tend to alter their phenotype in 2D systems since in real scenarios they are found in $3 \mathrm{D}$ environments. This phenotypic transformation of cells would however also happen in $2 \mathrm{D}$ cell cultures of macroscopic sizes, as explained in section 2.2 $[43,44]$. 
Several 3D microfluidic systems have been designed to evaluate the behaviour of osteogenic cells. For instance, a microfluidic device containing 3D circular microchambers was designed to simulate the formation of osteocytes' lacunae and canaliculi. The authors showed that osteocytes could be cultured in the 3D architecture using sophisticated and time-consuming techniques. Nevertheless, this system would not be achievable with conventional methods and allowed understanding of the mechanotransduction mechanisms on osteocytes [73]. In a completely different approach, channels of 1 $\mathrm{mm}$ height were designed to culture 3D micromasses of human bone marrow-derived MSCs under continuous flow with a gradient concentration of morphogens. By perfusing cell micromasses instead of using traditional macromass pellet cultures, a 34-fold higher percentage of proliferating cells was observed at day 7. Moreover, cells spread homogeneously throughout the whole volume and didn't show heterogeneity in cell responses, which are usually observed in macromass pellet cultures. In addition to this, supplementing the cells with a combination of Wnt3a and FGF2 factors, a pre-chondrogenic expansion similar to that occurring in the limb bud was observed [69].

In any case, when designing a new microfluidic system, it is important to keep in mind that the configuration and dimensions of the culture channel may compromise cell perfusion and potentially lead to misleading results. For example, a reduction of 4 times in channel width (from 0.80 to $0.20 \mathrm{~mm}$ ) and of 5 times in channel height (from 0.10 to $0.02 \mathrm{~mm}$ ) was shown to-increase cell death of osteocytes (MLO-Y4), probably due to the lack of nutrients reaching those cells at a greater distance from the inlet [74].

\subsection{Mechanotransduction}

\section{Theoretical background}

Mechanobiology is a field of biology that evaluates how physical forces affect cell behaviour, regulating their function and fate [75-78]. The molecular mechanisms that trigger these responses are known collectively as mechanotransduction. In general terms, applying certain mechanical forces to cells may trigger biochemical cascades via force-sensitive ion channels or membrane proteins [75-78], which may influence cell fate. In turn, these mechanical forces can cause rearrangements of the cytoskeleton and affect cell attachment, which again may influence on cell fate [75,78-80].

Embracing the importance of applying mechanical stimuli to mineralize ECM in vitro (see "Dynamic cultures" in section 2), microfluidic systems can be used as a tool to subtly apply these mechanical stresses (with lower forces and higher precision than a bioreactor) and therefore more finely resemble the physiological stimuli. Despite the fact that the principles ruling the physical stimuli (i.e. compression, tension or shear stress) is the same in macroscale reactors and microfluidic systems, the latter present three main advantages for mechanotransduction studies. First, microfluidics may provide a relevant size and geometry to recreate in vivo interstitial fluid flow [6]. Second, small displacements (at a physiological length scale) may be performed to produce the desired surface strain, minimizing volumetric displacements of fluid that could modify cell function [81]. Third, they enable the simultaneous refinement of biomechanical and biochemical properties, which permits having a matrix with a chemical gradient at the same time as a physical stimuli is applied [70,82].

\section{Mechanotransduction in $2 D$ and $3 D$ cultures}

There are different approaches in applying mechanical forces to cells using microfluidic-based systems. In this section, we will focus on the use of shear stress and compressive strength to evaluate cell behaviour (Figure 3). Nevertheless, cells in a 2D configuration can also be mechanically stimulated by applying hydrostatic pressure, rotatory shear or by deforming a substrate (bending, uniaxial or biaxial in-plane deformation) [81]. Cells encapsulated in a 3D configuration can also be deformed by applying uni- or biaxial pressure to the structure. In this case, the fluid transiently bears the loads and applies a hydrostatic pressure to cells [81]. Generally, the magnitude of strain, applied strain field and frequency 
of stimulation determines cell response [81,83]. Being able to control such force parameters within a culture system allows for more reliable in vitro studies in the bone regeneration field.

Readers are directed to a review by Kurth et al. [84] for further mechanotransduction studies using microfluidics systems for other applications than bone regeneration.
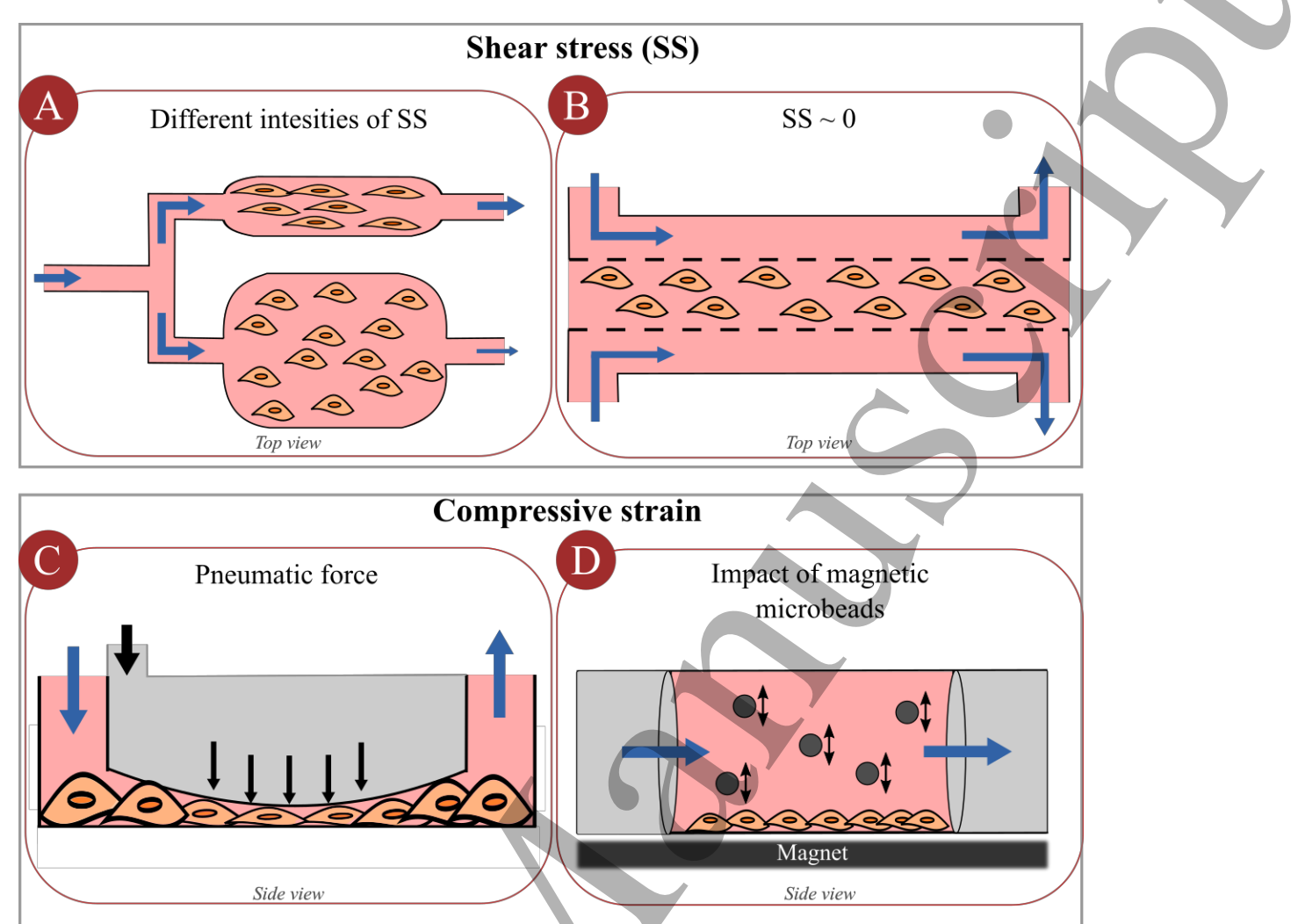

Figure 3. Methodologies to evaluate shear stress and compressive strain of cells-on-chip. (a) Application of different flow rates of shear stress; (b) no shear stress in the culture region. (c) Compressive strain applied by means of a flexible membrane or (d) by the impact of magnetic microbeads. Dashed lines represent a semipermeable membrane or pillars.

\section{Shear stress}

The laminar flow regime achieved in microfluidic-based systems intrinsically creates a shear stress by means of a controlled flow, which may stimulate the cells cultured in the channel [84]. The shear stress is directly related to the flow in the channel and inversely proportional to its dimensions (width and height). The range of shear stress impacting the differentiation of precursor cells into osteoblasts is unclear, since disperse numbers have been reported (Table 3). Moreover, calcium influx in osteoblasts is shear stress-dependent at least in the range of $0.3-3 \mathrm{dyn} / \mathrm{cm}^{2}$ [85].

A large number of studies have evaluated how fluid flow shear stress affects bone cells. A simple design including four culturing channels with different widths (between 400 and $3200 \mu \mathrm{m}$ ) was used to evaluate how shear stress influenced the intracellular calcium concentration of primary osteoblasts. By simply applying a fixed flow rate $(31 \mu 1 / \mathrm{min})$ the cells in each chamber were subjected to different shear stresses, between $0.3 \mathrm{dyn} / \mathrm{cm}^{2}$ and $2.4 \mathrm{dyn} / \mathrm{cm}^{2}$ (Figure 3a). Under shear stress conditions, the cells increased the intracellular calcium concentration in order to prevent excessive calcium influx. The peak of intracellular calcium concentration measured exhibited a linear relationship with the shear stress present in each channel. The ability of cells to autoregulate themselves produced a stable intracellular calcium concentration, which was reduced to values similar to the initial ones after the flow was stopped [85]. Similarly, another study evaluated the intracellular calcium concentration of osteoblast-like cells (MG-63) when cultured in different types of flow: unidirectional steady (constant 
at $20 \mathrm{dyn} / \mathrm{cm}^{2}$ ), unidirectional pulsatile (between 10 and $20 \mathrm{dyn} / \mathrm{cm}^{2}$ ), or oscillatory ( $2 \mathrm{~Hz}$ frequency, shear stress between 0 and $20 \mathrm{dyn} / \mathrm{cm}^{2}$ ). Interestingly, osteoblasts showed a larger production of calcium flicker in the oscillatory flow. The authors hypothesized that the formation of a stretch-activated ion channel (TRPM7) could act as a mechanical sensor in osteoblasts cells and convert the mechanical force into biochemical signals (i.e. calcium flickers) [86]. In partial contradiction with these results, it was found that mouse calvarial osteoblast-like cells (MC3T3-E1) reorganized their F-actin only under steady flow experiments and not when an oscillatory fluid flow (sinusoidal profile at a frequency of $1 \mathrm{~Hz}$ ) was applied, despite having the same value of shear stress $\left(12 \mathrm{dyn} / \mathrm{cm}^{2}\right)$. The actin reorganization was ascribed to an attempt by cells to reinforce their mechanical structure [87].

Leclerc et al. cultured osteoblast-like cells (MC3T3-E1) in flat static Petri dishes and in a 3D channel under dynamic flow $\left(0.05 \mathrm{dyn} / \mathrm{cm}^{2}\right)$. They observed that even though cells under dynamic flow grew preferably near areas of lower shear stress, cells expressed a higher ALP activity than cells under static cultures. A faster flow rate $\left(0.7 \mathrm{dyn} / \mathrm{cm}^{2}\right)$ caused cell detachment $24 \mathrm{~h}$ after culturing under dynamic conditions [7]. Altmann et al. obtained contradictory results while evaluating the differentiation of human alveolar bone osteoblasts towards osteogenic paths, comparing static vs. dynamic conditions with two different methods. On one hand, ECM deposition of osteocalcin, osteonectin, and collagen I was stronger in dynamic conditions, as observed by immunohistochemistry staining of monolayer cultures. On the other hand, gene expression results showed that both early (ALPL and COL1A1) and late (SPARC) osteoblast differentiation markers were down-regulated when cells were under dynamic flow, whereas another late osteoblast differentiation marker (BGLAP) did not show significant differences. Regarding the cell morphology, fluid flow caused cells to radically evolve from having a sheet-like morphology to become a multicellular aggregate with a rounded architecture. While the cells under dynamic flow formed their new morphology within $24 \mathrm{~h}$, the morphology did not change after modifying the flow conditions to static [88].

Several relevant studies of mechanotransduction with microfluidic systems have evaluated the differentiation of MSCs into other cell lineages. Mechanotransduction studies with MSCs generally aim to evaluate the effect of shear stress on cell behaviour, their proliferation rate, and morphology. Park et al. determined that fluid flow creating a low shear stress of $0.14 \mathrm{dyn} / \mathrm{cm}^{2}$ enhanced cell proliferation of primary human MSCs (hMSCs) in comparison to cells under static flow. However, the proliferation rate was linearly reduced by increasing the shear stress from 0.14 to $0.5 \mathrm{dyn} / \mathrm{cm}^{2}$. Interestingly, hMSCs showed a strong alignment with the flow, with no correlation observed within the range of shear stress applied [89]. Zheng et al. evaluated the morphology in real-time of rat bone marrow-derived MSCs under physiological shear stress $\left(13 \mathrm{dyn} / \mathrm{cm}^{2}\right)$ for $60 \mathrm{~min}$ and compared it to cells under static conditions. The difference observed was important, since cells under flow started contracting 10 min after the flow started, showing a $25 \%$ of their original area. However, $20 \mathrm{~min}$ later, cells managed to extend again and, by the end of the experiment, their area was recovered to $60 \%$. As expected, no morphology change was observed in the cells under static conditions. Rat MSCs under a larger shear stress (98 and $\left.147 \mathrm{dyn} / \mathrm{cm}^{2}\right)$ showed a similar contraction and re-spread phenomena, the higher the shear stress applied, the shorter the time before contraction started. The authors also proved that integrin's $\beta-1$ subunit played an important role in the rMSC behaviour under flow, since by blocking this integrin the percentage of contracted cell number dropped, the contraction time postponed, and the recovery of cell area increased [90]. In another study, hMSCs were grown with and without osteogenic supplements in the media and a shear stress between 4 and 22 dynes $/ \mathrm{cm}^{2}$ was applied for 4 and 8 days. The results indicated that while hMSCs grown without osteogenic supplements expressed osteogenic genes in linear correlation with the shear stress applied, the addition of osteogenic factors to the microfluidic culture did not cause any clear trend. In any case, the expression of osteogenic genes by hMSCs under shear stress was between 2 and 8 times higher than in cases under static conditions [91]. Kim et al. investigated the mechanism behind the differentiation of hMSCs towards the osteogenic lineage cultured at low values of shear stress. A flow of $0.274 \mu \mathrm{l} / \mathrm{min}\left(0.1 \mathrm{dyn} / \mathrm{cm}^{2}\right)$ was already enough to upregulate some osteogenic markers 
by about $50 \%$. The authors proved that this could be due to the TAZ target genes (CTGF and Cyr61), strong mediators of interstitial flow [92].

Microfluidic systems have also been designed to minimize shear stress and, therefore, avoid compromising the viability of delicate human cells. Harink et al. made two simple designs that kept the shear stress in the culture chamber cells down to zero. A first design consisted of a straight, elongated chamber separated from two lateral flow channels by an array of micropillars (Figure 3b). A second design consisted of a square culture chamber with $4 \mathrm{U}$-shaped flow channels on each side, also separated from the culture chamber by an array of micropillars; a fifth channel crossing the culture chamber in the diagonal was only used for cell loading. These two designs were developed in glass-glass microfluidic channels and allowed for real-time imaging of osteoblast cells under hypoxia conditions [72]. 
Table 3. Effect of shear stress (SS) in osteoblasts and MSCs.

\begin{tabular}{|c|c|c|c|c|c|c|}
\hline Cell type & Type of flow & $\begin{array}{l}\text { Shear stress (SS; } \\
\left.\text { dyn } / \mathrm{cm}^{2}\right)\end{array}$ & $\begin{array}{l}\text { Flow } \\
(\mu 1 / \mathrm{min})\end{array}$ & Dimensions $(\mu \mathrm{m})$ & Cell response & Reference \\
\hline \multirow{2}{*}{$\begin{array}{l}\text { Primary } \\
\text { human } \\
\text { alveolar } \\
\text { bone } \\
\text { osteoblasts } \\
\text { (PHABO) }\end{array}$} & $\begin{array}{l}\text { Microfluidic } \\
\text { culture, } \\
\text { conditions (chip placed } \\
\text { in a Petri dish) }\end{array}$ & 0 & 0 & \multirow[t]{2}{*}{$\begin{array}{l}\text { Cubic } \\
\text { microcavities } \\
\text { (300 } \mu \mathrm{m} \text { side } \\
\text { length) }\end{array}$} & \multirow{2}{*}{$\begin{array}{l}\text { - Flow induces the formation of } \\
\text { multicellular aggregates. } \\
\text { - Viability of cells is flow } \\
\text { dependant: } 30 \text { and } 60 \mu \mathrm{l} / \mathrm{min} \\
\text { shows a reduced viability of } \\
\text { cells. } \\
\text { - A fluid flow of } 15 \mu \mathrm{l} / \mathrm{min} \\
\text { applied for } 7 \text { days, down- } \\
\text { regulated early differentiation } \\
\text { biomarkers (e.g. ALPL and } \\
\text { COL1A1) while up-regulating } \\
\text { late differentiation markers } \\
\text { (e.g. SPARC). }\end{array}$} & \multirow[t]{2}{*}{ [88] } \\
\hline & $\begin{array}{l}\text { Microfluidic 3D culture } \\
\text { under flow perfusion }\end{array}$ & & $\begin{array}{l}15,30 \text { and } \\
60\end{array}$ & & & \\
\hline $\begin{array}{l}\text { Rat primary } \\
\text { osteoblasts }\end{array}$ & Microfluidic 2D culture & $0.3,0.6,1.2,2.4$ & 31 & $\begin{array}{l}\mathrm{W}=400,800, \\
1600,3200\end{array}$ & $\begin{array}{l}\text { The cytosolic calcium } \\
\text { concentration increases with } \\
\text { SS. }\end{array}$ & {$[85]$} \\
\hline \multirow{4}{*}{$\begin{array}{l}\text { Mouse } \\
\text { osteoblast- } \\
\text { like cells }\end{array}$} & $\begin{array}{l}\text { 3D } \\
\text { channel wicrofluidic } \\
\text { media. Media wath } \\
\text { changed } \\
\text { every second day }\end{array}$ & 0 & 0 & \multirow[t]{2}{*}{$\begin{array}{l}\mathrm{W}=150,1=400, \\
\mathrm{~h}=100\end{array}$} & \multirow{2}{*}{$\begin{array}{l}\text { - Cells grew better on areas of } \\
\text { low } \mathrm{SS} \text {. } \\
\text { - } 35 \mu \mathrm{l} / \mathrm{min} \text { flow rate resulted in } \\
\text { very low cell viability and even } \\
\text { cell detachment. } \\
\text { - ALP activity was } 7 \text { times } \\
\text { higher in microfluidic } \\
\text { conditions ( } 5 \mu \mathrm{l} / \mathrm{min}) \text { than in } \\
\text { static conditions. }\end{array}$} & \multirow[t]{2}{*}[7]{} \\
\hline & $\begin{array}{lr}\text { 3D } & \text { microfluidic } \\
\text { channel, } & \text { continuous } \\
\text { perfusion } & \end{array}$ & $0.05-0.7$ & $5-35$ & & & \\
\hline & $\begin{array}{l}48 \text { well plate (static } \\
\text { conditions) }\end{array}$ & 0 & 0 & N.A. & \multirow{2}{*}{$\begin{array}{l}\text { A significantly higher ALP } \\
\text { activity was observed in the } \\
\text { microfluidic channel in } \\
\text { comparison with the well plate, }\end{array}$} & \multirow[t]{2}{*}{ [93] } \\
\hline & $\begin{array}{l}\text { 2D Microchannel with } \\
\text { dynamic flow }\end{array}$ & 0.07 & 0.2 & $\begin{array}{l}\mathrm{w}=200 \\
\mathrm{~h}=100\end{array}$ & & \\
\hline
\end{tabular}




\begin{tabular}{|c|c|c|c|c|c|c|}
\hline & & & & & $\begin{array}{l}\text { independently of the type of } \\
\text { medium used: } \\
\text { a) standard medium } \\
\text { b) differentiation medium }+0.1 \\
\mu \mathrm{M} \text { dexamethasone }+50 \mathrm{mM} \\
\beta \text {-glycerolphosphate }+50 \mu \mathrm{l} / \mathrm{ml} \\
\text { ascorbic acid } \\
\text { c) differentiation medium } \\
\text { supplemented with } 50 \mathrm{ng} / \mathrm{ml} \\
\text { BMP-2 }\end{array}$ & \\
\hline & $\begin{array}{|lr|}\text { 2D } & \text { microfluidic } \\
\text { channel } & \text { (Flexcell } \\
\text { Streamer from } & \text { Flexcell } \\
\text { International) } & \text { with } \\
\text { steady flow } & \\
\end{array}$ & Peak: 12 & N.I. & N.I. & $\begin{array}{l}\text { - F-actin reorganized under } \\
\text { steady flow and formed stress } \\
\text { fibers. } \\
\text { - In contrast, } 1 \mathrm{~h} \text { under dynamic } \\
\text { oscillatory flow did not result in }\end{array}$ & {$[87]$} \\
\hline & \begin{tabular}{|lr}
$2 \mathrm{D}$ & microfluidic \\
channel & (Flexcell \\
Streamer from & Flexcell \\
International) & with \\
oscillatory flow & $(1 \mathrm{~Hz})$ \\
\end{tabular} & Peak: 12 & N.I. & N.I. & such a reorganization. & \\
\hline & $\begin{array}{l}\text { 2D microfluidic } \\
\text { channel (multi-shear } \\
\text { microfluidic device for } \\
\text { low SS) }\end{array}$ & $\begin{array}{l}1.5 \cdot 10^{-5}, \quad 7.7 \cdot 10^{-5} \\
5.26 \cdot 10^{-4}, \\
4.12 \cdot 10^{-3}\end{array}$ & $\begin{array}{l}0.06,0.08 \\
0.1,0.15\end{array}$ & $\begin{array}{l}\text { Four chambers of } \\
\text { identical size: } \\
\mathrm{w}=1265,1= \\
4265, \mathrm{~h}=100\end{array}$ & $\begin{array}{l}-1.5 \cdot 10^{-5}<\mathrm{SS}<5.26 \cdot 10^{-4}: \\
\text { promoted cells proliferation } \\
\text { and differentiation. } \\
-\mathrm{SS}>4.12 \cdot 10^{-3}: \text { inhibited cells } \\
\text { proliferation } \\
\text { differentiation. }\end{array}$ & {$[94]$} \\
\hline & $\begin{array}{l}2 \mathrm{D} r \text { microfluidic } \\
\text { channel (FlexFlow } \\
\text { chamber from } \\
\text { International) }\end{array}$ & $\begin{array}{l}\text { a) Steady flow: } 2 \text {, } \\
15 \text {, or } 25 \text { for } 120 \\
\text { min. } \\
\text { b) Static: } 0\end{array}$ & N.I. & N.I. & $\begin{array}{l}\text { Speed at which osteoblasts } \\
\text { migrate increased in a } \\
\text { dependent manner with SS. }\end{array}$ & {$[95]$} \\
\hline $\begin{array}{l}\text { (MC3T3- } \\
\text { E1) }\end{array}$ & $\begin{array}{l}\text { 2D microfluidic } \\
\text { channel for single cell } \\
\text { culture. }\end{array}$ & $8-30$ & $\begin{array}{l}233 @ 1 \\
\mathrm{~Pa} \\
468 @ 2 \mathrm{~Pa}\end{array}$ & $\begin{array}{l}\text { Cells grew on } \\
\text { cell sites }(\varnothing=15 \\
\mu \mathrm{m}) \text { that were }\end{array}$ & $\begin{array}{l}\text { A higher SS and compressive } \\
\text { stress }(233 \mu \mathrm{m} / \mathrm{min} @ 1 \mathrm{~Pa}) \\
\text { stimulated cells by slightly }\end{array}$ & {$[96]$} \\
\hline
\end{tabular}




\begin{tabular}{|c|c|c|c|c|c|c|}
\hline \begin{tabular}{|l} 
Human \\
osteoblast- \\
like cells \\
$(\mathrm{MG}-63)$
\end{tabular} & $\begin{array}{l}\text { Cells experience both } \\
\text { SS and compressive } \\
\text { stress }\end{array}$ & & & $\begin{array}{l}\text { connected } r \\
\text { each other with } \\
\text { thin }(3 \mu \mathrm{m}) \text { and } \\
\text { long }(30 \mu \mathrm{m}) \\
\text { bridges }\end{array}$ & $\begin{array}{l}\text { modifying the frequency and } \\
\text { intensity of intracellular } \\
\text { calcium expression of single } \\
\text { cells. }\end{array}$ & \\
\hline & $\begin{array}{l}2 \mathrm{D} \quad \text { microfluidic } \\
\text { channel with static flow }\end{array}$ & & 0 & $\begin{array}{l}\mathrm{w}=1500,1= \\
4 \cdot 10^{4}, \mathrm{~h}=75\end{array}$ & $\begin{array}{l}\text { - The percentage of MG-63 } \\
\text { cells increasing intracellular }\end{array}$ & [86] \\
\hline & $\begin{array}{lr}2 \mathrm{D} & \text { microfluidic } \\
\text { channel } & \text { with } \\
\text { unidirectional steady } \\
\text { flow }\end{array}$ & & N.I. & & $\begin{array}{l}\text { calcium was: } \\
17 \% \text { under steady flow }(\mathrm{SS}= \\
20 \text { ) } \\
43 \% \text { under } 0.2 \mathrm{~Hz} \text { pulsatile }\end{array}$ & \\
\hline & $\begin{array}{l}\text { 2D microfluidic } \\
\text { channel with } \\
\text { unidirectional pulsatile } \\
\text { flow }(0.1-1.5 \mathrm{~Hz})\end{array}$ & $10-20$ & N.I. & & $\begin{array}{l}\text { flow } \\
74 \% \text { under } 0.2 \mathrm{~Hz} \text { oscillatory } \\
\text { flow }\end{array}$ & \\
\hline & $\begin{array}{l}2 \mathrm{D} \text { microfluidic } \\
\text { channel with } \\
\text { oscillatory flow }(0.1- \\
1.5 \mathrm{~Hz})\end{array}$ & $0-20$ & N.I. & & & \\
\hline & $\begin{array}{l}\text { 2D microfluidic } \\
\text { channel }\end{array}$ & $\begin{array}{l}\text { Middle area of } \\
\text { channel: } 0.14\end{array}$ & 0.274 & $\begin{array}{l}\mathrm{w}=4000,1=10 \\
000, \mathrm{~h}=200\end{array}$ & $\begin{array}{l}\text { SS increased } \\
\text { localization of } \begin{array}{r}\text { nuclear } \\
\text { (transcriptional coactivator }\end{array} \\
\text { with PDZ-binding motif), } \\
\text { alkaline phosphatase activity } \\
\text { and the expression of } \\
\text { osteoblastic marker genes } \\
\text { (Runx2, DLX5, Msx2) }\end{array}$ & [92] \\
\hline MSCs & $\begin{array}{l}\text { 2D microfluidic } \\
\text { channel with flow } \\
\text { (PEG solutions used to } \\
\text { ensure same SS at } \\
\text { different flow rates) }\end{array}$ & $\begin{array}{l}0.14,0.27,0.4,0.5 \\
(0.05,0.1,0.15 \\
\text { and } 0.2 \mathrm{M} \text { PEG } \\
\text { solution, } \\
\text { respectively) }\end{array}$ & $\begin{array}{l}0.14,0.27, \\
0.41 \text { and } \\
0.54(0.05, \\
0.1,0.15 \\
\text { and } 0.2 \mathrm{M} \\
\text { PEG }\end{array}$ & $\begin{array}{l}\mathrm{w}=4000,1= \\
4000, \mathrm{~h}=80\end{array}$ & $\begin{array}{l}\text { - Cell proliferation decreased } \\
\text { with higher SS. } \\
\text { - Morphological changes } \\
\text { observed at SS of } 0.4 \mathrm{dyn} / \mathrm{cm}^{2} \\
\text { or higher. }\end{array}$ & [89] \\
\hline
\end{tabular}




\begin{tabular}{|c|c|c|c|c|c|c|}
\hline & & & $\begin{array}{l}\text { solution, } \\
\text { respectivel } \\
\text { y) }\end{array}$ & & & \\
\hline & $\begin{array}{l}\text { a) 2D microfluidic } \\
\text { channel under static } \\
\text { flow }(7-11 \text { days }) \\
\text { b) 2D microfluidic } \\
\text { channel under static } \\
\text { flow }(7-11 \text { days })+24 \\
\text { h SS period either at } \\
\text { day } 3 \text { or at day } 7\end{array}$ & $\begin{array}{l}4,15 \text { and } 22 \text { for } \\
24 \mathrm{~h} \text { (starting at } \\
\text { day } 3 \text { or } 7)\end{array}$ & N.I. & $\begin{array}{l}\mathrm{w}=25000,1= \\
\text { N.I., } \mathrm{h}=220\end{array}$ & $\begin{array}{l}\text { - SS stimulates hMSCs towards } \\
\text { an osteoblastic phenotype (ALP } \\
\text { released in the media). } \\
\text { - Total amount of ALP (cellular } \\
+ \text { released) was higher after } 7 \\
\text { days of static culture prior SS } \\
\text { was applied (greater sensitivity } \\
\text { to SS after a longer period in } \\
\text { static conditions). }\end{array}$ & [91] \\
\hline Rat MSCs & $\begin{array}{l}\text { 2D microfluidic } \\
\text { channel with interval } \\
\text { flow }\end{array}$ & 13 & N.I. & N.I. & $\begin{array}{l}\text { Cells went through a } \\
\text { contraction and re-spread } \\
\text { process when subjected to SS. }\end{array}$ & [90] \\
\hline \multirow{2}{*}{$\begin{array}{l}\text { Co-culture } \\
\text { of: } \\
\text { osteocyte- } \\
\text { like cells } \\
\text { (MLO-Y4) } \\
\text { and } \\
\text { osteoclast- } \\
\text { like cells } \\
\text { (RAW264.7) }\end{array}$} & $\begin{array}{l}\text { 2D microfluidic } \\
\text { channel with steady } \\
\text { flow to stimulate } \\
\text { osteocytes } \\
\text { mechanically }\end{array}$ & 16.5 & $10.3-103$ & \multirow[t]{2}{*}{$\begin{array}{l}\mathrm{W}=1000,1= \\
1600, \mathrm{~h}=60\end{array}$} & \multirow{2}{*}{$\begin{array}{l}\text { - Real-time signalling between } \\
\text { cells showed that osteoclasts } \\
\text { had a higher cell density (higher } \\
\text { proliferation, lower apoptosis } \\
\text { and/or decreased migration) } \\
\text { when in contact with } \\
\text { unstimulated osteocytes. } \\
\text { - Osteocytes produce high } \\
\text { cytosolic Ca at higher SS. }\end{array}$} & \multirow[t]{2}{*}{ [70] } \\
\hline & $\begin{array}{l}\text { 2D microfluidic } \\
\text { channel with steady } \\
\text { flow for unstimulated } \\
\text { osteocytes and } \\
\text { osteoclast-like cells }\end{array}$ & $\begin{array}{l}-2.8 \text { at } \\
\text { osteoclasts } \\
\text { channel } \\
-0.7 \text { at } \\
\text { unstimulated } \\
\text { osteocytes } \\
\text { channel }\end{array}$ & 1 & & & \\
\hline
\end{tabular}

N.A. $=$ no applies; N. I. = not indicated in the original paper 


\section{Compressive strain}

Compressive strain has been applied to cells cultured in a microfluidic system by means of either a flexible membrane or by the impact of beads. Cyclic compressive stimulation was applied to hMSC by means of a pneumatic actuator with a flexible membrane (pressure between 1 and $20 \mathrm{kPa}$ at a frequency of $1 \mathrm{~Hz}$ for $10 \mathrm{~min}$ ) twice a day for 7 days (Figure 3c). The ALP activity and calcium deposition stained by Alizarin Red showed the highest results when the cells were stimulated at $5 \mathrm{kPa}$. This data indicated that micro cell stimulation induced an early differentiation towards the osteogenesis lineage [97].

Another approach to evaluating how compressive strain influences cell proliferation was tackled by impacting magnetic beads on osteoblast-like cells (MC3T3-E1) within a microfluidic-like system (Figure 3d). Beads of diverse sizes $(4.5,7.6$ and $8.4 \mu \mathrm{m}$ ) impacted cells at different frequencies and cell numbers were counted after one doubling of time. The authors proved that mechanical stimulation effectively influenced cell growth rate, which was in turn influenced by the cell cycle phase [98]. In general, it has been concluded that the cellular response to mechanotransduction depends on the type of stimulus, its magnitude and application (including potential static periods), and cell cycle phase $[98,99]$.

\subsection{Chemicals and gradients}

While the concentration of a chemical or growth factor may oscillate with time in a static culture, having a dynamic flow may ensure a constant concentration of the compound over time. Therefore, microfluidics can be used to evaluate how a constant concentration of a compound influences cultured cells. Specifically, Jang et al. cultured osteoblast-like (MC3T3-E1) cells in a microfluidic device and evaluated the effect of standard culture media or differentiation culture media (either supplemented with only $0.1 \mu \mathrm{M}$ dexamethasone or with both $0.1 \mu \mathrm{M}$ dexamethasone and $50 \mathrm{ng} / \mathrm{mL}$ BMP-2) [93]. The ALP results obtained by a microfluidic device (dynamic conditions with a flow rate of $0.6 \mu 1 / \mathrm{min}$ ) were compared to cells cultured in well plates under static conditions. When comparing the static and dynamic conditions, the microfluidic device resulted in ALP activity values up to 40 times higher than that of a well plate. As expected, the highest ALP production was observed for cells grown under both dexamethasone and BMP-2, followed by cells grown under only BMP-2 and finally by cells grown under standard media. Despite the interesting results, further studies are needed to determine whether the effect of the higher ALP activity of dynamic conditions is due to a constant concentration of the chemicals added, the fresh medium (containing full concentration of nutrients) and/or the shear stress effect in the cells [93].

The laminar flow characteristic of microfluidic devices allows the generation of chemical gradients. The range of chemical concentrations can either be created in solution (soluble gradients) or on the surface of a substrate (surface-bound gradients). There are two approaches to creating soluble gradients, flow-based and diffusion-based [62].

The flow-based gradient generation consists of flowing a dissolved chemical and a pristine solution through two inlets. Serial diluted solutions are created by mixing the solutions of branched channels, which creates a tree-like structure [100]. At the end of each channel, the flows can either be directed to separated chambers or they can flow next to each other and remain unmixed thanks to the laminar flow (Figure 4a).

$\mathrm{pH}$ gradients were created by means of a flow-based gradient, elegantly showing that such a parameter had a great influence on cell adhesion and migration. More specifically, osteoblasts (MG-63) were shown to adhere in less quantity on areas below $\mathrm{pH} 5$ and they were even able to migrate from a pH 5 to a pH 9 zone within 6 h of culture [101]. In another work, a flow-based gradient was designed to evaluate the effect of different concentrations of doxycycline, which is a BMP-2 expression modulator. The osteogenic potential of C9 cells (BMP-2 inducible expression cell line) grown in a microfluidic device under a gradient concentration of doxycycline was evaluated. The C9 cells showed a dosedependent differentiation towards osteogenic pathways with enhanced calcium deposits after 3 weeks 
of culture [102]. Interestingly, the authors showed that the absence of physical barriers in microfluidic systems (in comparison with well plates) allowed proteins secreted by cells to form tissue interfaces.

The diffusion-based gradient generator consists of mass transfer diffusion between two compounds flowing side-to-side along a channel (long enough to ensure diffusion, which is restricted in a laminar flow regime), creating a chemical gradient (Figure 4b). As an example, a chemical gradient of Cytochalasin D (original solution of $5 \mu \mathrm{g} / \mathrm{ml}$ ) was created along five independent cell culture chambers in free shear stress conditions. The authors proved that MG-63 osteosarcoma cells modified their morphology depending on the concentration of Cytochalasin D present in the specific area of the channel, which was in accordance with the actin polymerization inhibitor function of Cytochalasin $[103,104]$. Using a more advanced setup, Harink et al. presented a microfluidic chip with a square chamber of $650 \mu \mathrm{m}$ in length and $75 \mu \mathrm{m}$ in height, that allowed a four-way gradient by loading soluble compounds in orthogonal channels. This led to overlapping concentrations of the compounds. In this work, only one molecule was used, phenanthroline, which is a hypoxia-mimicking molecule that triggers the release of angiogenic factors. MG-63 osteosarcoma cells cultured with phenanthroline (range of 2.5$10 \mu \mathrm{M})$ and stained with H1F1 $\alpha$ exhibited a higher intensity of the nucleus than control cells. This indicated that MG-63 cells had a dose-dependent response in the range of phenanthroline tested [105].

In general, the use of microfluidic devices minimizes the number of chemical compounds used, which in some cases are expensive, potentially toxic and sometimes obtained from animal sources. Therefore, evaluating several chemical concentrations by means of a microfluidic gradient makes the study more affordable and sustainable. Moreover, it allows testing a continuous range of concentrations, instead of discrete values, which may be crucial in determining a threshold concentration. Furthermore, this is done using the same batch of cells in an area that is fed with a controlled and continuous amount of treatment agent, hence reducing the variability and improving the accuracy of the experiments $[102,104]$.

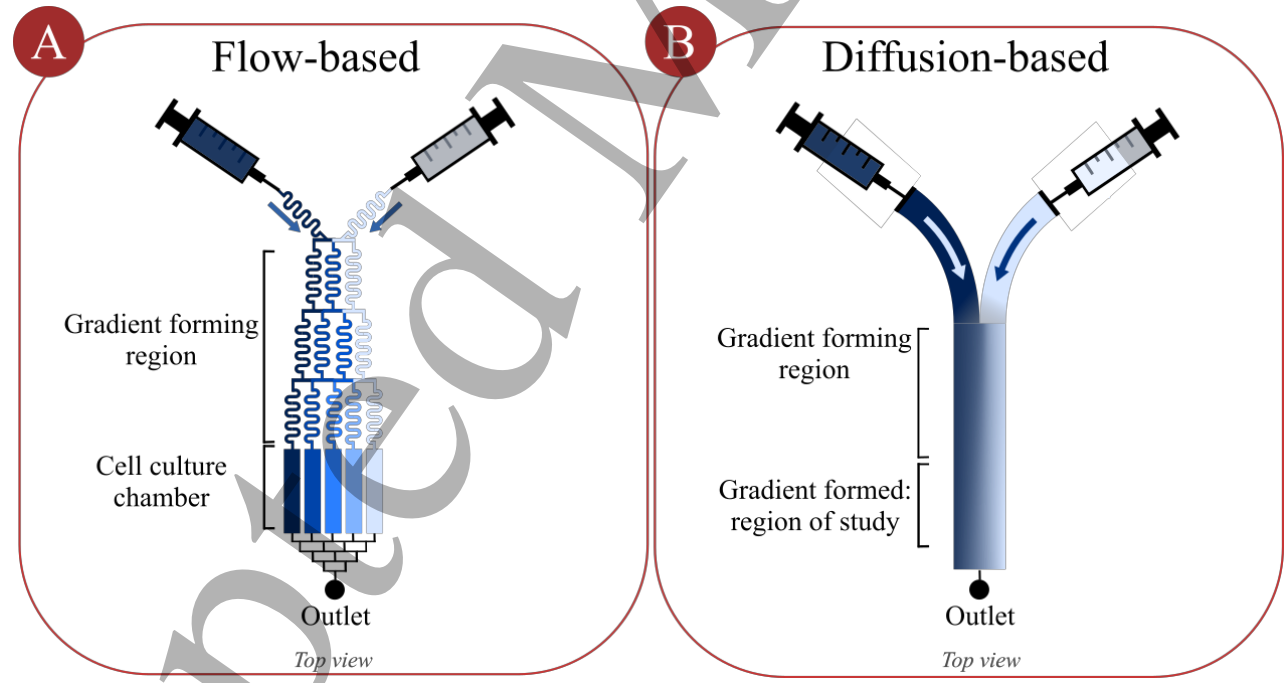

Figure 4. Scheme of two different ways to create a chemical gradient (soluble or surface-bound gradients) using either (a) a flow-based or (b) a diffusion-based gradient generator.

\subsection{Co-culture}

Microfluidic devices may be designed with the aim of co-culturing cells in indirect or direct contact with other cells. An indirect co-culture involves culturing cells with chemical signals released in-line by other cells. In this configuration, different cells can be cultured in different chambers either separated by channels or by a semipermeable membrane or by pillars. In contrast, in a direct co-culture, both cell types are cultured in the same chamber. There are two clear advantages of co-culturing cells at a micrometric scale. First, the chemical cues produced by cells can be directly streamed to other cells in 
real-time, without being altered due to the short transport distances [45]. Second, cell signalling is maximized due to reduced volume-per-cell ratios [8].

Wei et al. developed a microfluidic device to perform indirect co-cultures of macrophages and osteoblasts. Macrophages were either chemically (with an endotoxin, lipopolysaccharide) or physically (with PDMS debris) activated to burst the release of inflammatory cytokines, which were divided in a gradient generator. Each concentration of cytokines was evaluated for the release of prostaglandin E2 (PGE2) by osteoblasts [106]. This study proved that using such a microfluidic system instead of a conventional static co-culture provided two main advantages: 1) real-time transfer of the cytokines released by one cell type and influencing the behaviour of another cell type; 2) the linear cytokine gradient could be used in a high throughput assay.

Another approach to performing indirect co-culture in microfluidic devices consists of culturing a cell type with a conditioned medium from another cell type. A conditioned medium is usually enriched on cytokines and/or growth factors released by cells grown under particular conditions. Liu et al. used the conditioned medium from mechanically loaded (concentric fluid flow shear stress) pre-osteoblasts (MC3T3-E1) to determine their ability to affect load-driven paracrine signalling on endothelial cells (C166-GFP). The results showed that culturing endothelial cells with osteoblasts' conditioned medium enhanced both sprouting frequency and length, which was associated with the factors released by mechanically activated osteoblasts [107].

Direct co-cultures have also been performed in microfluidic devices. A microfluidic system consisting of two side-by-side channels with a microgroove area in between was designed to culture sensory neurons on one channel and osteoblasts in the other. The rationale for such a co-culture is that soluble factors produced by nerve fibers have been associated with changes in the activity of bone cells [108]. To promote organotypic cultures, dorsal root ganglion (previously mechanically dissociated) was added in the same channel as the embryonic sensory neurons. Scanning electron microscope (SEM) images showed a dynamic and close interaction between osteoblasts and sensory neurons [108]. Osteoblasts increased their metabolic activity when co-cultured in the microfluidic device in comparison to a well plate. The main advantage of such a microfluidic co-culture is that it provided a real-time exposure to secreted cytokines and that the dimensions permitted the extension of axons to reach such chemical attractors.

Finally, another approach that shows the versatility of microfluidic systems consisted of a device to culture all type of cells, including suspended cells (e.g. red blood cells), low-motility cells (e.g. leukocytes) and high-motility/swimming cells (e.g. planktonic bacteria). The particularity of this device is its high control of speed, with a high entrance speed and a low exit speed (lower than 1/100 of entrance flow) [109]. Such a device would permit the co-culture of cells with such different motilities to be retained and studied in the same system, allowing different avenues in the bone regeneration field to be explored.

\subsection{Combination of designs}

Microfluidic-based systems are versatile, allowing the simultaneous combination of two or more parameters (i.e. cell culture configuration, mechanotransduction, control of chemicals concentration flowed and co-cultures) in a microfluidic system. The combination of such parameters allows the creation of a more complex and relevant physiological system than those commonly achieved using well plates. This demonstrates their great potential.

For instance, mechanotransduction studies may be combined with chemical gradients or cocultures. Likewise, both a soluble and surface-bound gradient could be combined together by flowing a soluble-gradient on a channel that already has a surface-bound gradient. Another combination approach consisted of making gradients out of molecules released in situ by cells grown under co-culture conditions $[70,106]$. In a similar way, environmental conditions $\left(\mathrm{O}_{2}, \mathrm{CO}_{2}\right.$, etc.) can be combined with 
mechanotransduction, co-cultures or chemicals. For example, cells could be submitted to a hypoxiamimicking environment and a chemical gradient of a potential drug candidate could be tested to efficiently find an effective therapeutic concentration window [105].

Middleton et al. performed a complete study combining co-cultures of osteocytes and osteoclast precursors, which were stimulated at physiologically-relevant fluid flows. The design consisted of three parallel channels, separated by resistance side channels to minimize convection. Osteocytes (MLO-Y4 cells) were cultured in two side channels with either a mechanically stimulatory flow $\left(17 \mathrm{dyn} / \mathrm{cm}^{2}\right)$ or a non-stimulatory flow $\left(0.7 \mathrm{dyn} / \mathrm{cm}^{2}\right)$, while osteoclast precursors (RAW 264.7) were cultured in the middle channel with a non-stimulatory flow $\left(3 \mathrm{dyn} / \mathrm{cm}^{2}\right)$. Mechanically stimulatory flow was applied to the corresponding channel for $1 \mathrm{~h}$ per day and a perfusion flow was applied to all channels during the remaining $23 \mathrm{~h}$. The release of cytokines by osteocytes (both mechanically stimulated and not) reached the osteoclast precursors in a gradient manner and allowed cell behaviour in real-time signalling between different cell types to be evaluated. The study permitted bone remodelling steps to be described using these insights. The authors speculated that unstimulated osteocytes created an appropriate environment for osteoclasts to perform bone resorption. Afterwards, nearby osteocytes increased their mechanosensitivity and switched their function to promote osteoblastogenesis. The main advantage of this system is that physiologically relevant mechanotransduction produced real-time signalling between osteocytes and osteoclasts at physiological length scales [70].

\section{Microfluidics for evaluating the biological properties of biomaterials for bone tissue regeneration}

Microfluidics has recently emerged (from the 2010s) as a new technological platform to evaluate the biological properties of biomaterials using cell cultures. Although it is still in its infancy, it has already shown potential in evaluating the behaviour and differentiation of cells in a finely controlled environment. Biomaterials of different chemical nature (ceramics, polymers/gels, metals, and composites) have been integrated and evaluated in different types of microfluidic platforms providing new results that could not be obtained without the support of this technology.

In this section, we will approach different possibilities for investigating the biological properties of biomaterials using microfluidic devices: a) spatial configuration of the cells cultured on/in a biomaterial, b) mechanotransduction, c) chemicals and chemical gradients, d) co-cultures, e) screening and $\mathrm{f}$ ) combination of designs. Figure 5 represents some of the possible microfluidic designs integrating biomaterials that can be built to study biomaterial-cell interaction. 


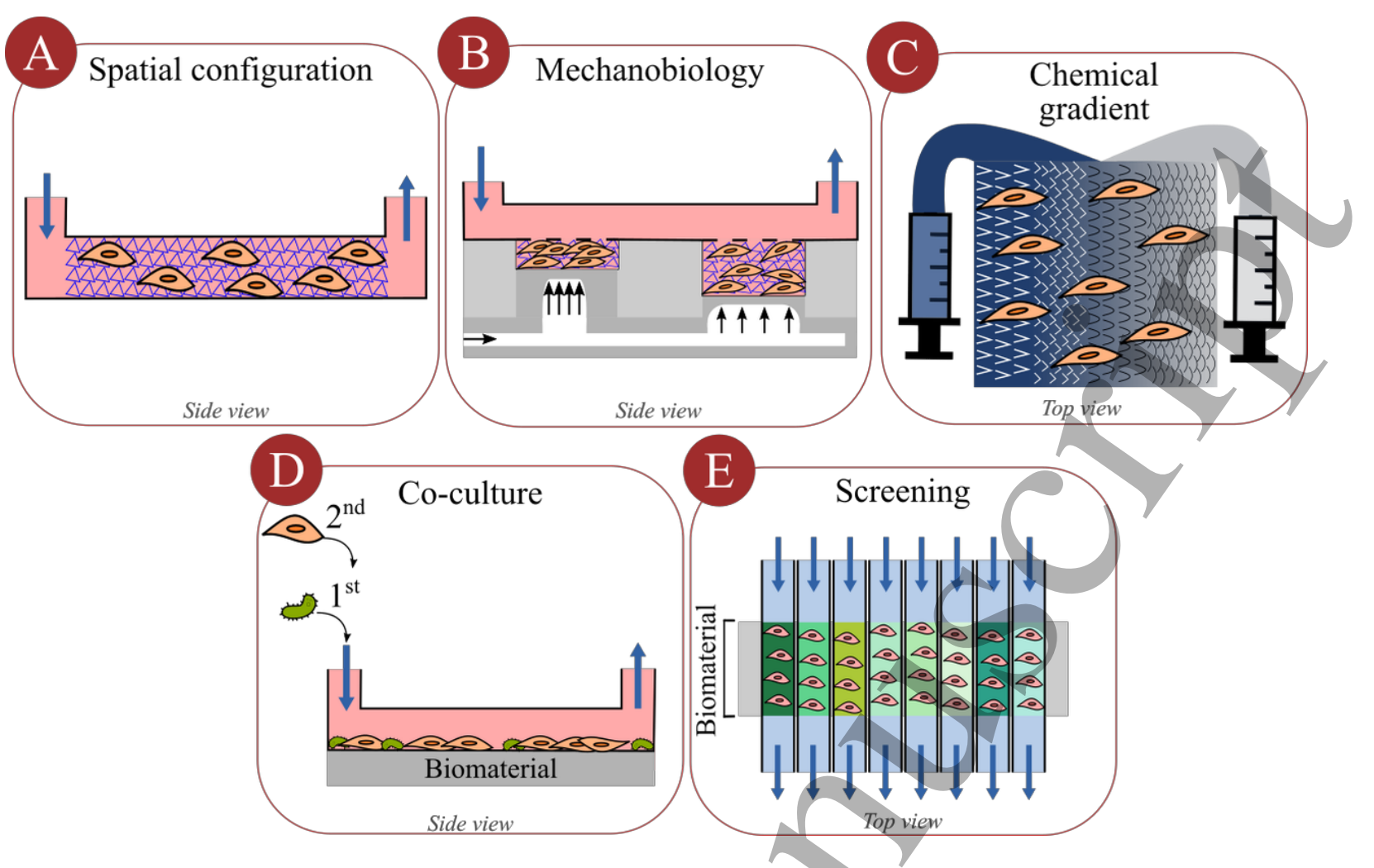

Figure 5. Potential biomaterials-on-chip designs. (a) Spatial configuration of the cells cultured on/in a biomaterial; (b) mechanotransduction; (c) chemical gradient; (d) co-cultures; (e) screening. Dashed lines represent a semipermeable membrane or pillars.

\subsection{Spatial configuration for cell culturing}

Biomaterials for bone regeneration have been integrated into microfluidic systems using different approaches. Depending on the material, cells have been cultured on the surface of flat (Figure 6a) or architectonically complex materials (Figure 6b), as well as inside porous materials (Figure 6c). The physico-chemical nature, dimensions, and shape of the biomaterial have a direct effect on cell behaviour $[45,110,111]$. Both quantitative and qualitative evaluations of cells can be performed with biomaterials integrated in a microfluídic system and, furthermore, cell number and reagent volumes are decreased [112]. However, some of the intrinsic challenges of 3D models are to homogeneously distribute the cells along the porous biomaterial [10], and to provide an efficient distribution of nutrients and wash out of waste products [ 11$]$.

The 2D approaches allow evaluation of osteoblast and MSC behaviour growing on a biomaterial under a continuous laminar flow, and therefore under a certain degree of shear stress. Stamp et al. and Hartmann et al. designed a system to culture osteoblast-like cells (Saos-2) on a titanium disc, whose available surface for cells was upside down [113,114]. A characteristic of this system was that a piezoelectric substrate was used to create an acoustic streaming, which guided a fluid flow of cells towards the available titanium surface. The authors observed that the cells detached over time even in static conditions due to gravity force. Moreover, the degree of detachment was approximately three times faster when a hydrodynamic force was present. Regarding cell adhesion, a roughness of $R_{q}=22$ $\mathrm{nm}\left(\mathrm{R}_{\mathrm{q}}\right.$ between 630 and $2 \mathrm{~nm}$ were evaluated) was optimum [114], whereas plain titanium was more preferable than a diamond-like carbon doped with silver [113].

There are several studies in which cells are cultured in microfluidic systems with a 3D configuration using polymers. Barata et al. developed a microfluidic device that integrated pyramids of dense polylactic acid (PLA) to evaluate how human osteoblast-like MG-63 cells would adhere to the surface of such architectures. The 3D pyramids of PLA were contained at the bottom of a channel and 
were bonded to a PDMS lid to assemble the final microfluidic device (Figure 6b). The design allowed to either perfuse the flow through the main channel or to diffuse it using side channels. The study proved that both the height of the PLA pyramids and the grid-like structure of their walls affected cell distribution. Overall, this work exemplifies how complex micrometric 3D structures of a polymer can be successfully integrated into a microfluidic device [115].

Another microfluidic platform consisted of two parallel lines of pillars between which a HEMA-MMA-MAA terpolymer was entrapped. Bone marrow mesenchymal stem cells (BMSCs) were cultured in the polymer under a continuous flow of osteogenic media. This platform allowed for cellcell and cell-material interactions in a 3D environment. The authors proved the importance of having a low cell seeding flow $(0.83 \mu \mathrm{l} / \mathrm{min}$ or lower) to improve cell viability, since doubling the flow significantly decreased cell viability. Cells stretched along the direction of fluid flow in the channel 72 $\mathrm{h}$ after media perfusion. This proved that cells could preserve their 3D cytoarchitecture and possibly present a realistic behaviour when cultured in an appropriate 3D in vitro model [112].

In a different approach, microcarriers were applied in microfluidics with the aim of evaluating the biological properties of biomaterials in a $3 \mathrm{D}$ configuration. Abeille et al. created a microfluidic system in which dextran (polysaccharide) spherical microcarriers ( $175 \mu \mathrm{m}$ particle size) were placed in an independent channel separated from the flow channel by a semipermeable membrane. The system was designed to allow cell adhesion on the microcarriers, provided by the diffusion of fresh nutrients through the semipermeable membrane (Figure 6c). This design allowed for a constant flow of fresh nutrients, while avoiding cell damage caused by shear stress forces. This platform permitted the cells growing on the microcarriers after immunostaining to be imaged by confocal microscopy. The authors foresee that this platform could be used to create 3D cell spheroids for drug discovery applications, since the cells grown on microcarriers developed cell-cell junctions [116]. In a slightly different approach, microcarriers composed of biphasic calcium phosphate (BCP), with a size range between 20 and $25 \mu \mathrm{m}$, were used to create a 3D physiologically-relevant lacuna to guide osteocyte network. For this purpose, cells were cultured on BCP microcarriers in a PDMS chamber and perfused with culture media for 21 days. The cell occupancy in interstitial sites caused an exponential pressure increase over time throughout the perfusion chamber (around 10 days), and the porosity was estimated to linearly decrease. Cells were also able to create significant amounts of ECM and the osteocyte-specific markers released by cells followed a similar trend to that observed in vivo [117].

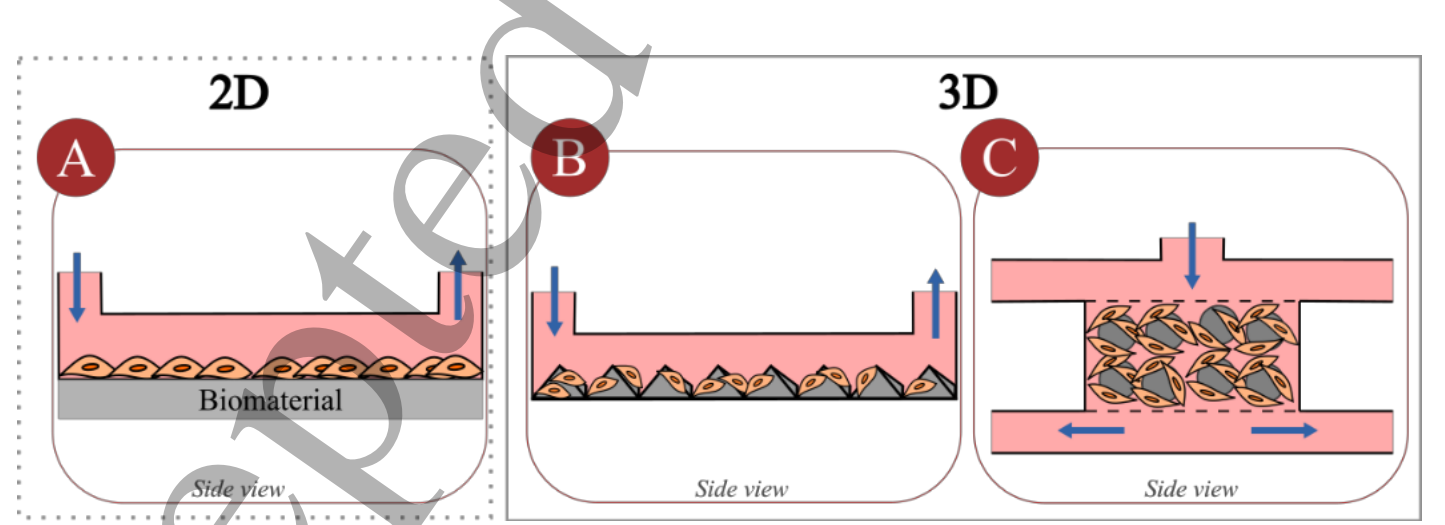

Figure 6. Biomaterials-on-chip with different 2D and 3D spatial configurations. Cells growing (a) on a flat biomaterial; (b) on the surface of an architectonically complex biomaterial; (c) in the interstitial pores of an entanglement of spherical microcarriers. Dashed lines represent a semipermeable membrane or pillars.

\subsection{Mechanotransduction}

As previously explained, microfluidic technology has opened the door for performing precise mechanotransduction studies, since using bioreactors flow parameters cannot be so finely controlled. Moraes et al. created a microarray of cell-loaded poly(ethylene glycol) (PEG) constructs of different 
diameters that were cross-linked by means of UV light. Mouse MSCs (C3H1071/2) were encapsulated in the hydrogels. A single pressure source was applied to compress the hydrogels in different levels and the constructs were imaged to determine cellular and nucleus deformation. This microarray was useful to test how mechanical response affected cell behaviour [118]. Despite not being related to bone regeneration, a study that exemplifies well the effect of topography and stiffness of an inert 2D substrate (PDMS) in a microfluidic system was performed using fibroblasts (NIH 3T3). A manual cross-roller positioning stage was used to mechanically compress the PDMS microchannel in which cells were cultured. Cells under compression strain were found to align along the direction of microchannels and perpendicular to the direction of compression. The cell area was inversely proportional to the time (between 3 and 12h) and magnitude (10 and 17\%) of compression strain applied [119].

\subsection{Chemical concentrations and gradients}

Biomaterials integrated into microfluidic devices can be used to culture cells under a controlled concentration of a chemical cue, growth factor, or a soluble gradient. Another possibility is to use microfluidic devices to create a superficial pattern on a biomaterial, for example, immobilizing biological molecules or a chemical compound in a gradient-fashion (surface-bound gradient).

A first approach used a gradient generator to prepare a hydrogel with different mechanical properties distributed in a gradient-fashion (Figure 7a). For this purpose, two monomers with different molecular weights flowed in the initial branches, and the hydrogel was polymerized in the channel by exposing it to UV, finally creating a poly(ethylene glycol) diacrylate with a gradient in mechanical properties. The authors also used the gradient generator/to create/acryloyl-poly(ethylene glycol) hydrogels with a gradient of RGDS (ligand for cell adhesion with peptide sequence Arg-Gly-Asp-Ser) on its surface. The number of adhered cells correlated linearly with the density of RGDS present on the hydrogel, as observed by culturing cells on the hydrogels out of the chip [120]. In a similar way, Liu et al. used a microfluidic gradient generator to create a gradient of RGDS peptide on a polydimethylsiloxane (PDMS). Bone marrow-derived MSCs adherence was directly dependant on the superficial RGDS density [121]. In a different study, the effect of a material topography was evaluated by creating a gradient of roughnesses (Ra between 2.6 and $163.6 \mathrm{~nm}$ ) on a PDMS surface with a thermoresponsive polymer (NIPAM). MSCs were cultured on the rough PDMS under microfluidic conditions (flow between 6.7 and $33.3 \mu \mathrm{l} / \mathrm{min}$ ), and it was observed that cells attached in greater numbers and spread more widely on the smoother substrates [122]. Unfortunately, these studies did not include a parallel static culture in macroscopic conditions and therefore it is difficult to determine the differences that would have been found.

A second approach to create a gradient of molecules, in this case, bone morphogenetical proteins (BMP-2), was proposed by Pagano et al. The authors created a chip with three side-by-side channels: the middle one integrating cells loaded in a collagen I gel, a side channel flowing with medium supplemented with BMP-2, and the remaining side channel flowing with fresh medium (Figure 7b). Chemotaxis experiments showed that hMSCs moved towards those micro-areas with higher BMP-2 concentrations [123].

A third approach described by Shi et al. consisted of creating a three-layered culturing condition system in a cell-agarose composite embedded in a PDMS microfluidic system (Figure 7c). One side area contained osteogenic media, another side area chondrogenic media and the area in-between had a gradient of both conditions. The authors proved that adipose-derived MSCs differentiated either into osteoblasts or chondrocytes in direct correlation with the area of the gel in which they were grown [124]. 


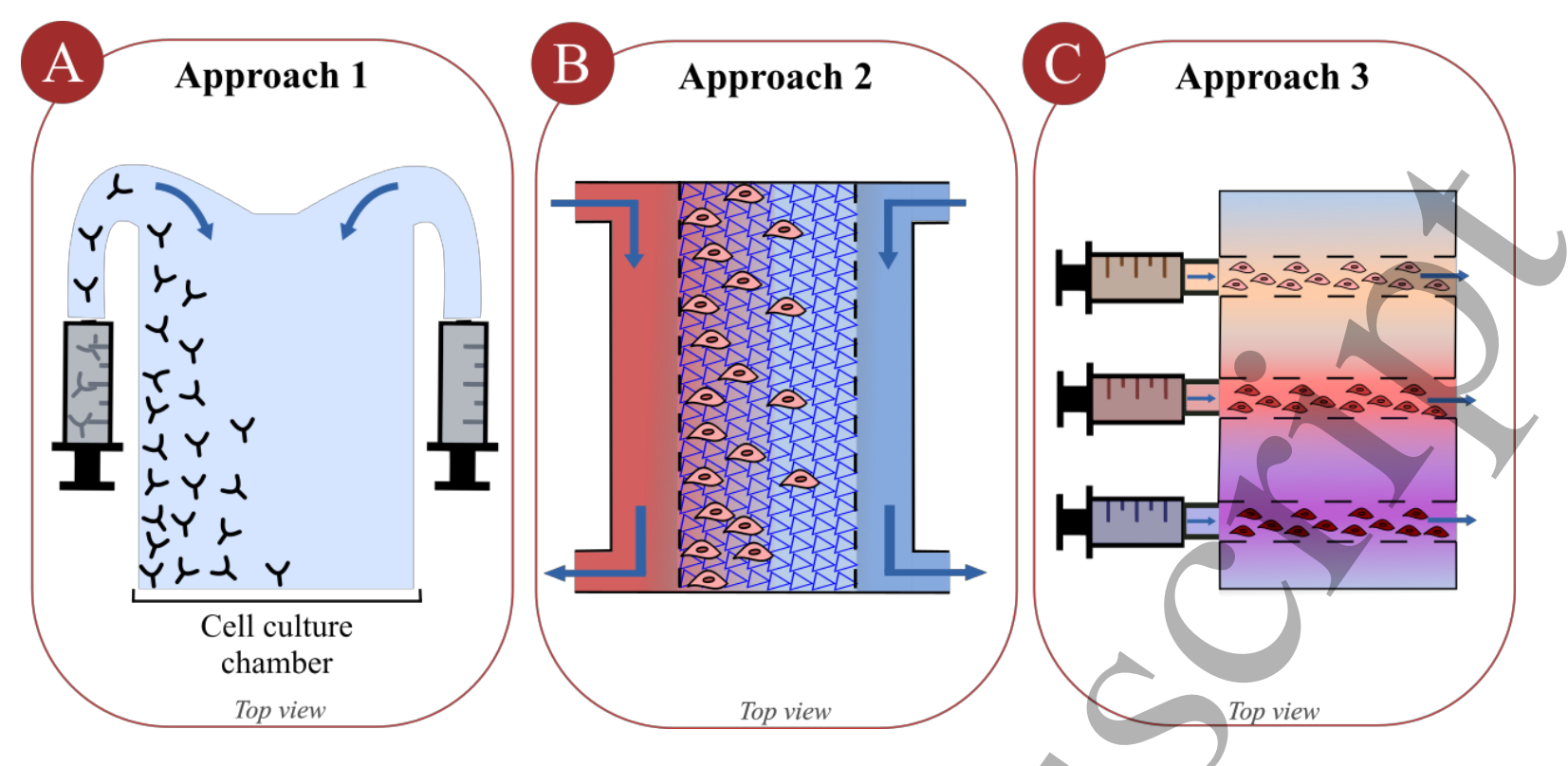

Figure 7. Different approaches to creating gradients on a biomaterial-on-chip. (a) Surface-bound gradient created on the surface of a biomaterial; (b) one-chemical gradient in a polymeric matrix; (c) several chemicals gradient in a polymeric matrix. Dotted lines represent a semipermeable membrane or pillars.

\subsection{Co-cultures}

Direct and indirect co-cultures on/in biomaterials integrated into microfluidic devices have been performed. The influence of angiogenic factors, released by a mechanically stimulated osteoblast cell line (MC3T3-E1), on regulating angiogenesis of an endothelial cell line (C166-GFP) was evaluated with an indirect co-culture. For this purpose, endothelial cells were grown in a collagen gel embedded in a microchannel that mimicked a vessel geometry. An adjacent channel was either filled with conditioned media from mechanically stimulated MC3T3-E1, or with fresh media. The osteoblasts had been previously mechanically stimulated by keeping cultured plates on an orbital shaker $(2 \mathrm{~h}$ a day for 2 days), which induced concentric fluid flow shear stress, and the conditioned media was collected. The paracrine factors present in the conditioned media induced endothelial cell proliferation, migration and sprouting, proving the crosstalk between mechanically stimulated bone cells and endothelial cells [107].

Microfluidic devices have also been used to grow more than one cell type on a biomaterial. Lee's research group developed direct co-cultures of eukaryotic cells (pre-osteoblasts-like MC3T3-E1) and procaryotic cells (Staphylococcus epidermis) on the surface of a titanium TiAl6V4 alloy integrated into a microfluidic device (Figure 5d). S. epidermis was first inoculated, being maintained in still conditions in the channel for $10 \mathrm{~min}$. Afterwards, osteoblasts were seeded and kept still in the channel for $4 \mathrm{~h}$ before starting to flow media at a rate of $0.1 \mu \mathrm{l} / \mathrm{min}$. The co-culture was kept for $25 \mathrm{~h}$ and the authors showed that while pre-osteoblasts were slightly compromised at the lower cell density of $S$. epidermis $\left(10^{2} \mathrm{CFU} / \mathrm{ml}\right)$, most of pre-osteoblasts died as bacteria proliferated $\left(10^{5} \mathrm{CFU} / \mathrm{ml}\right)$ [125]. This microfluidic system allowed in vivo-like situations provided by the size of the channels and the continuous flow to be simulated. This in turn permitted the influence of $S$. epidermis on pre-osteoblasts viability to be determined. This is an example of a physiologically and clinically relevant in vitro model successfully developed to study bacterial infection associated with implants.

Lee's research group performed a similar work in which biphasic calcium phosphate (BCP) nanoparticles were dispersed in a poly(D,L-lactic-co-glycolic) acid matrix to evaluate the effect of rifampicin antibiotic-loaded materials to kill S. epidermis. In this case, micropatterns of ceramic materials were printed on a glass slide, with a PDMS channel integrated on top. In line with their previous study, bacteria were initially inoculated for $1 \mathrm{~h}$ in static conditions, followed by the seeding of pre-osteoblasts. The co-culture was run for 13 days at a $0.8 \mu 1 / \mathrm{min}$ flow rate. The authors proved that 
rifampicin-loaded ceramics were able to completely kill bacteria without affecting the pre-osteoblasts, whereas in the presence of the antibiotic-free ceramics, bacteria proliferated and compromised osteoblast viability [126]. These studies, besides allowing cell behaviour to be continuously monitored, were performed using lower amounts of biomaterials and a larger number of replicates than conventional standard methods.

Tri-cultures have also been performed using a 3D microfluidic culture platform. A study performed by Bruce et al. aimed to evaluate how human bone marrow-derived MSCs (hBMSC) and human osteoblasts (HOB) influence the development of lymphoblastic leukemia since it is known that this cancer is initiated in the bone marrow. Leukemic cells (SUP-B15) were grown in monoculture as well as in tri-culture with hBMSC and HOB using 2D static, 3D static and 3D microfluidic models. In the 2D static model, hBMSC and HOB were seeded at $80-90 \%$ confluence onto glass coverstips, and $24 \mathrm{~h}$ later SUP-B15 cells were seeded onto the monolayer. In the 3D static model, a cell-laden collagen was loaded into the microchannels. Finally, in the 3D microfluidic model, the microchannels were filled as in the 3D static model and a flow of $0.21 \mu \mathrm{l} / \mathrm{min}$ was perfused. For the three models described, SUPB15: hBMSC:HOB cells were mixed at a 10:2:2 ratio. The results proved that both static and dynamic 3D microchannel cultures showed a higher chemoresistance of tumor cells against cytarabine (a commonly used chemotherapeutic drug) in comparison to standard 2D static models. Moreover, within the 3D microchannel cultures, tricultures showed a higher chemoresistance than monocultures. This study is another demonstration of the relevance of microfluidic systems to develop improved in vitro models to mimic in vivo conditions [127].

\subsection{Screening}

Microfluidic devices allow biomaterials and environmental conditions (e.g. media composition, level of shear stress, etc.) to be screened by placing them in an array-manner (Figure 5e) $[14,128]$. This permits the biological properties of biomaterials to be evaluated in two different scenarios: 1) the same type of material under different environmental conditions; 2) different type of materials under the same environmental conditions. In both cases, obtaining a large number of replicates improves the statistical analysis, and may even allow observing statistical differences that would have not been seen otherwise.

Ramdongbang et al. proved that it is possible to create a microfluidic chip containing 200 microcontainers $(\mathrm{w}=1000 \mu \mathrm{m}, 1=1000 \mu \mathrm{m}, \mathrm{h}=500 \mu \mathrm{m})$ to evaluate cell behaviour in contact with different concentrations of graphene oxide nanoparticles. The microwell-based biochip used only $5 \mu 1$ media/well and $2.5 \mu \mathrm{g}$ nanoparticle/well, whereas the standard assay used $1000 \mu \mathrm{l}$ (200-fold higher) and $500 \mu \mathrm{g} / \mathrm{well}$ (20-fold higher), respectively. However, in the present format, the microwell-based chip only allowed for short experiments $(6 \mathrm{~h})$, whereas the standard assay could allow for a week-long experiment. The microwell-based design was successfully used to determine the optimal concentration of graphene oxide to enhance cell growth of pre-osteoblasts. The size of the microcontainers limited the evaluation to nanoparticles, while other shapes such as sheet, plate and rods had to be tested in standard well plates [129].

\subsection{Combination of designs}

The versatility of microfluidic-based systems allows the integration of biomaterials, which may have different physico-chemical properties (i.e. topography, roughness, etc.), with the simultaneous combination of two or more parameters (i.e. spatial configuration of cells cultured on/in biomaterial, mechanotransduction, chemicals \& gradients, co-cultures, etc.) [104]. Since this is still a young field, there are however a limited number of published works exploring all these possibilities.

A combination approach was used to develop a microfluidic in vitro model to mimic bone, with its mineral and extracellular matrix. Such a work is a milestone in the field of microfluidics for bone regeneration. Jusoh et al. proposed a model for 3D microvascular bone angiogenesis consisting of a central channel in which fibrin and hydroxyapatite (HA, up to $0.5 \%$ ) were embedded (bone channel), a 
lateral channel containing endothelial cells, and a second lateral channel containing fresh media. Angiogenesis experiments were performed and the length of angiogenic sprout growth for different concentrations was quantified. The authors concluded that the concentration of HA is crucial: the appropriate amount of HA particles might accelerate angiogenesis, since HA is able to adsorb growth factors such as VEGF, whereas an excessive concentration of HA might decrease the space for angiogenesis [82].

\section{Conclusions and future perspectives: bridging the gap between biomaterials and microfluidics}

In the past 10 years, microfluidic systems have allowed to refine in vitro/models. A striking example is the field of organ-a-on-chip [15-17], which has generated a lot of interest in the scientific community and beyond. Recently, emerged spin-off companies (e.g. Emulate Inc., TissUse GmbH, CN Bio Innovations, MIMETAS) and pharmaceutical companies have started to adopt this new standard [22], with economical support from the US Food and Drug Administration or the European Commission.

In this review, we have described the different options available for evaluating the biological properties of biomaterials, using the versatility of microfluidic technology. By using the available and constantly improving technological toolbox that microfluidics can provide, more physiologically relevant studies $[6,7,46,130]$ can be performed with only a small footprint, using reduced amounts of reagents (cells, growth factors, antibodies, etc.), and hence decreasing the costs. Many parameters can be controlled in these types of arrangements, providing an adequate flow rate to mimic biological conditions, allocating cells in a confined 3D environment as well as combining all these requirements with specific gradients of chemical cues or co-cultures.

However, the use of microfluidic devices to perform biological studies on biomaterials is more challenging than using standard cultures [23]. It requires a certain level of expertise in the research team [23], as well as specialized equipment to microfabricate or 3D print the systems [46]. Thus, it might reduce or delay the widespread acceptance to a broader audience. Nevertheless, both the interest from the research community and the available technology are increasing the number of companies selling specialized parts needed to implement such a methodology.

The challenge of using microfluidic techniques may be higher for some particular biomaterials. For example, the integration and stability under flow of particularly fragile or highly porous materials might be difficult, since the flow could be easily blocked by the detachment of some small parts. Heterogeneous and macroporous materials might also be challenging cases, requiring either bigger structures to contain several repetitions of the structural unit or parallel units to contain the individual parts.

In order for this young field to gain attraction, studies comparing microfluidic-tested biomaterial with standard methods will be needed. This may be decisive in proving that the results obtained with this technology are more relevant than traditional methods, and thus motivate testing in more complex configurations. To achieve this, inter-laboratory assay efforts should be carried out to evaluate the performance of conventional biomaterials in static conditions (conventional method), dynamic conditions at the macro-scale (i.e. bioreactors) and dynamic conditions at the micro-scale (using the microfluidic methodology). Furthermore, laboratory consortia should implement standardized bioassays adapted to microfluidic samples. The outcome of such a multi-centre study and adapted standardized bio-assays would allow the young methodology to be validated to a level that can satisfy the general scientific community.

The integration of biomaterials into microfluidic systems is a nascent field, yet benefiting from the momentum created by organ-on-a-chip. To keep it growing, strong inter-disciplinary teams need to bring their own expertise to show the actual value of the technology. By doing so, more relevant in vitro 
models can be created to accelerate biomaterial characterization and potentially introduce new materials, faster and in a safer way, to the market.

\section{Acknowledgments}

G. Mestres acknowledges Swedish Council Formas (\#2016-00781), Swedish Council Vetenskapsrådet (\#2017-05051) and Göran Gustaffson Foundation (\#1841) for financial support. 


\section{References}

[1] Engler A J, Sen S, Sweeney H L and Discher D E 2006 Matrix elasticity directs stem cell lineage specification Cell 126 677-89

[2] Vogler E A 2012 Protein adsorption in three dimensions Biomaterials 33 1201-37

[3] Perez R A and Mestres G 2016 Role of pore size and morphology in musculo-skeletal tissue regeneration Mater. Sci. Eng. C 61 922-39

[4] Hulsart-Billström G, et al. 2016 A surprisingly poor correlation between in vitro and in vivo testing of biomaterials for bone regeneration: Results of a multicentre analysis Eur. Cells Mater. 31 312-22

[5] Mark D, Haeberle S, Roth G, Von Stetten F and Zengerle R 2010 Microfluidic lab-on-a-chip platforms: Requirements, characteristics and applications Chem. Soc. Rev. $391153-82$

[6] Riehl B and Lim J 2012 Macro and microfluidic flows for skeletal regenerative medicine Cells 1 1225-45

[7] Leclerc E, David B, Griscom L, Lepioufle B, Fujii T, Layrolle P and Legallaisa C 2006 Study of osteoblastic cells in a microfluidic environment Biomaterials 27 586-95

[8] Domenech M, Yu H, Warrick J, Badders N M, Meyvantsson I, Alexander C M and Beebe D J 2009 Cellular observations enabled by microculture: Paracrine signaling and population demographics Integr. Biol. $1267-74$

[9] Wu H W, Lin C C and Lee G Bin 2011 Stem cells in microfluidics. Biomicrofluidics 513401

[10] Andersson H and van den Berg A 2004 Microfabrication and microfluidics for tissue engineering: state of the art and future opportunities Lab Chip 498

[11] Gao D, Liu H, Jiang Y, Lin J M, Gao D, Liu H and Jjang Y 2012 Recent developments in microfluidic devices for in vitro cell culture for cell-biology research $\operatorname{Tr} A C$ - Trends Anal. Chem. 35 150-64

[12] Ni M, Tong W H, Choudhury D, Rahim N A A, Iliescu C and Yu H 2009 Cell culture on MEMS platforms: A review Int. J. Mol. Sci. $105411-41$

[13] Huh D, Hamilton G A and Ingber D E 2011 From 3D cell culture to organs-on-chips Trends Cell Biol. 21 745-54

[14] Pihl J, Sinclair J, Karlsson M and Orwar O 2005 Microfluidics for cell-based assays Mater. Today 8 46-51

[15] Huh D, Matthews B, Mammoto A, Montoya-Zavala M, Hsin H I D 2010 Reconstituting organ-level lung functions on a chip Science (80-. ). 328 1662-8

[16] Booth R and Kim H 2012 Characterization of a microfluidic in vitro model of the blood-brain barrier ( $\mu \mathrm{BBB})$ Lab Chip 12 1784-92

[17] Yeon J H, Na D, Choi K, Ryu S W, Choi C and Park J K 2012 Reliable permeability assay system in a microfluidic device mimicking cerebral vasculatures Biomed. Microdevices 14 $1141-8$

[18] Griep L M, et al. 2013 BBB on CHIP: Microfluidic platform to mechanically and biochemically modulate blood-brain barrier function Biomed. Microdevices 15 145-50

[19] Grosberg A, Alford P W, McCain M L and Parker K K 2011 Ensembles of engineered cardiac tissues for physiological and pharmacological study: Heart on a chip Lab Chip 11 4165-73

[20] Kim H J, Huh D, Hamilton G and Ingber D E 2012 Human gut-on-a-chip inhabited by microbial flora that experiences intestinal peristalsis-like motions and flow Lab Chip 12 216574

[21] Williamson A, Singh S, Fernekorn U and Schober A 2013 The future of the patient-specific Body-on-a-chip Lab Chip 13 3471-80

[22] Skardal A, et al. 2017 Multi-tissue interactions in an integrated three-tissue organ-on-a-chip platform Sci. Rep. 7 1-16

[23] Baker M 2011 Tissue models: A living system on a chip Nature 471 661-5

[24] Young E W K and Simmons C A 2010 Macro- and microscale fluid flow systems for endothelial cell biology Lab Chip 10 143-60

[25] Abbott R D and Kaplan D L 2015 Strategies for improving the physiological relevance of human engineered tissues Trends Biotechnol. 33 401-7 
[26] Dånmark S, Gladnikoff M, Frisk T, Zelenina M, Mustafa K, Russom A and Finne-Wistrand A 2012 Development of a novel microfluidic device for long-term in situ monitoring of live cells in 3-dimensional matrices Biomed. Microdevices 14 885-93

[27] Bancroft G N, Sikavitsas V I, van den Dolder J, Sheffield T L, Ambrose C G, Jansen J A and Mikos A G 2002 Fluid flow increases mineralized matrix deposition in 3D perfusion culture of marrow stromal osteoblasts in a dose-dependent manner PNAS 99 12600-5

[28] Wu H W, Lin C C, Hwang S M, Chang Y J and Lee G Bin 2011 A microfluidic device for chemical and mechanical stimulation of mesenchymal stem cells Microfluid. Nanofluidics 11 $545-56$

[29] Piekarski K 1970 Fracture of bone J. Appl. Phys. 41 215-23

[30] Rubin C T and Lanyon L E 1984 Regulation of bone formation by applied dynamic loads $J$. Bone Jt. Surg. 66 397-402

[31] Lanyon L E 1987 Functional strain in bone tissue as an objective, and controlling stimulus for adaptive bone remodelling $J$. Biomech. 20 1083-93

[32] Jones H H, Priest J D, Hayes W C, Tichenor C C and Nagel D A 1977 Humeral hypertrophy in response to exercise in Response to Exercise J. Bone Jt. Surg. 59 204-8

[33] Chilibeck P D, Sale D G and Webber C E 1995 Exercise and bone mineral density. Sports Med Sport. Med. 19 103-22

[34] Biering-Sorensen F, Bohr H H and Schaadt O P 1990 Longitudinal study of bone mineral content in the lumbar spine, the forearm and the lower extremities after spinal cord injury Eur. J. Clin. Invest. $20330-5$

[35] Owan I, Burr D B, Turner C H, Qiu J, Tu Y, Onyia J E and Duncan R L 1997 Mechanotransduction in bone: osteoblasts are more responsive to fluid forces than mechanical strain Am. Physiol. Soc. 273 C810-5

[36] Weinbaum S, Cowin S C and Zeng Y 1994 A model for the excitation of osteocytes by mechanical loading-induced bone fluid shear stresses J. Biomech. 27 339-60

[37] Wang L, Fritton S P, Weinbaum S and Cowin S C 2003 On bone adaptation due to venous stasis J. Biomech. 36 1439-51

[38] Hoppe A, Güldal N S and Boccaccini A R 2011 Areview of the biological response to ionic dissolution products from bioactive glasses and glass-ceramics Biomaterials 32 2757-74

[39] Engel E, Del Valle S, Aparicio C, Altankov G, Asin L, Planell J a and Ginebra M-P 2008 Discerning the role of topography and ion exchange in cell response of bioactive tissue engineering scaffolds. Tissue Eng. Part A 14 1341-51

[40] Sadowska J M, Guillem-Marti J, Espanol M, Stähli C, Döbelin N and Ginebra M P 2018 In vitro response of mesenchymal stem cells to biomimetic hydroxyapatite substrates: A new strategy to assess the effect of ion exchange Acta Biomater. 76 319-32

[41] Bacakova L, Filova E, Parizek M, Ruml T and Svorcik V 2011 Modulation of cell adhesion, proliferation and differentiation on materials designed for body implants Biotechnol. Adv. 29 739-67

[42] Lai M, Jin Z and Su Z 2017 Surface modification of TiO2nanotubes with osteogenic growth peptide to enhance osteoblast differentiation Mater. Sci. Eng. C 73 490-7

[43] Albrecht D R, Underhill G H, Wassermann T B, Sah R L and Bhatia S N 2006 Probing the role of multicellular organization in three-dimensional microenvironments Nat. Methods $\mathbf{3}$ 369-75

[44] Benya P D and Shaffer J D 1982 Dedifferentiated chondrocytes reexpress the differentiated collagen phenotype when cultured in agarose gels Cell 30 215-24

[45] Tandon N, Marolt D, Cimetta E and Vunjak-Novakovic G 2013 Bioreactor engineering of stem cell environments Biotechnol. Adv. 31 1020-31

[46] Wu H-W, Lin C-C and Lee G-B 2011 Stem cells in microfluidics. Biomicrofluidics 513401

[47] Duval K, Grover H, Han L-H, Mou Y, Pegoraro A F, Fredberg J and Chen Z 2017 Modeling Physiological Events in 2D vs. 3D Cell Culture Physiology 32 266-77

[48] Vetsch J R, Müller R and Hofmann S 2015 The evolution of simulation techniques for dynamic bone tissue engineering in bioreactors J. Tissue Eng. Regen. Med. 9 903-17 
[49] Orr D E and Burg K J L 2008 Design of a modular bioreactor to incorporate both perfusion flow and hydrostatic compression for tissue engineering applications Ann. Biomed. Eng. 36 1228-41

[50] Tehranirokh M, Kouzani A Z, Francis P S and Kanwar J R 2013 Microfluidic devices for cell cultivation and proliferation Biomicrofluidics 7 051502-1-32

[51] Marolt D, et al. 2012 Engineering bone tissue from human embryonic stem cells Proc. Natl. Acad. Sci. 109 8705-9

[52] Hillsley M V and Frangos J A 1994 Bone tissue engineering: the role of interstitial fluid flow Biotechnol. Bioeng. 43 573-81

[53] Price C, Zhou X, Li W and Wang L 2011 Real-time measurement of solute transport within the lacunar-canalicular system of mechanically loaded bone: Direct evidence for load-induced fluid flow J. Bone Miner. Res. 26 277-85

[54] Scaglione S, Wendt D, Miggino S, Papadimitropoulos A, Fato M, Quarto R and Martin I 2008 Effects of fluid flow and calcium phosphate coating on human bone marrow stromal cells cultured in a defined 2D model system J. Biomed. Mater. Res. - Part A 86 411-9

[55] Yeatts A B, Geibel E M, Fears F F and Fisher J P 2012 Human mesenchymal stem cell position within scaffolds influences cell fate during dynamic culture Biotechnol. Bioeng. 109 2381-91

[56] Bartnikowski M, Klein T J, Melchels F P W and Woodruff M A 2014 Effects of scaffold architecture on mechanical characteristics and osteoblast response to static and perfusion bioreactor cultures Biotechnol. Bioeng. 111 1440-51

[57] Baas E, Kuiper J H, Yang Y, Wood M A and El Haj A J 2010 In vitro bone growth responds to local mechanical strain in three-dimensional polymer scaffolds J. Biomech. 43 733-9

[58] Song K, Liu T, Cui Z, Li X and Ma X 2008 Three-dimensional fabrication of engineered bone with human bio-derived bone scaffolds in a rotating wall vessel bioreactor J. Biomed. Mater. Res. - Part A 86 323-32

[59] Zhang Z Y, Teoh S H, Chong W S, Foo T T, Chng Y C, Choolani M and Chan J 2009 A biaxial rotating bioreactor for the culture of fetal mesenchymal stem cells for bone tissue engineering Biomaterials 30 2694-704

[60] Godara P, McFarland C D and Nordon R E 2008 Design of bioreactors for mesenchymal stem cell tissue engineering J. Chem. Technol. Biotechnol. 83 408-20

[61] Vunjak-Novakovic G, Meinel L, Altman G and Kaplan D 2005 Bioreactor cultivation of osteochondral grafts Orthod. Craniofacial Res. 8 209-18

[62] Barata D, Van Blitterswijk C and Habibovic P 2016 High-throughput screening approaches and combinatorial development of biomaterials using microfluidics Acta Biomater. 34 1-20

[63] Chung S, Sudo R, MacK P J, Wan C R, Vickerman V and Kamm R D 2009 Cell migration into scaffolds under co-culture conditions in a microfluidic platform Lab Chip 9 269-75

[64] Cimetta E and Vunjak-Novakovic G 2014 Microscale technologies for regulating human stem cell differentiation Exp Biol Med 239 1255-63

[65] Diao J, et al. 2006 A three-channel microfluidic device for generating static linear gradients and its application to the quantitative analysis of bacterial chemotaxis Lab Chip 6 381-8

[66] Jeon N L, Dertinger S K W, Chiu D T, Choi I S, Stroock A D and Whitesides G M 2000 Generation of solution and surface gradients using microfluidic systems Langmuir 16 8311-6

[67] Squires T M and Quake S R 2005 Microfluidics: Fluid physics at the nanoliter scale Rev. Mod. Phys. 77 977-1026

[68] Toner M and Irimia D 2005 Blood-on-a-Chip Annu. Rev. Biomed. Eng. 7 77-103

[69] Occhetta P, Visone R and Rasponi M 2017 High-throughput microfluidic platform for 3D cultures of mesenchymal stem cells Methods Mol. Biol. 1612 303-23

[70] Middleton K, Al-Dujaili S, Mei X, Günther A and You L 2017 Microfluidic co-culture platform for investigating osteocyte-osteoclast signalling during fluid shear stress mechanostimulation J. Biomech. 59 35-42

[71] Shaegh S A M, et al. 2016 A microfluidic optical platform for real-time monitoring of $\mathrm{pH}$ and oxygen in microfluidic bioreactors and organ-on-chip devices Biomicrofluidics 10044111 
[72] Harink B, Le Gac S, Barata D, Van Blitterswijk C and Habibovic P 2014 Lab on a Chip Microtiter plate-sized standalone chip holder for microenvironmental physiological control in gas-impermeable microfluidic devices Lab Chip 14 1816-20

[73] You L, Temiyasathit S, Tao E, Prinz F and Jacobs C R 2008 3D Microfluidic approach to mechanical stimulation of osteocyte processes Cell. Mol. Bioeng. 1 103-7

[74] Wei C, et al. 2015 Osteocyte culture in microfluidic devices Biomicrofluidics 9014109

[75] Orr A W, Helmke B P, Blackman B R and Schwartz M A 2006 Mechanisms of mechanotransduction Dev. Cell 10 11-20

[76] Fletcher D A and Mullins R D 2010 Cell mechanics and the cytoskeleton Nature $\mathbf{4 6 3}$ 485-92

[77] Janmey P A, Winer J P, Murray M E and Wen Q 2010 The hard life of soft cells J. Cell Biol. 66 597-605

[78] Huang H 2004 Cell mechanics and mechanotransduction: pathways, probes, and physiology AJP Cell Physiol. $287 \mathrm{C} 1-11$

[79] Sepulveda J L, Gkretsi V and Wu C 2005 Assembly and signaling of adhesion complexes Curr. Top. Dev. Biol. 68 183-225

[80] Walker J L, Fournier A K and Assoian R K 2005 Regulation of growth factor signaling and cell cycle progression by cell adhesion and adhesion-dependent changes in cellular tension Cytokine Growth Factor Rev. 16 395-405

[81] Moraes C, Sun Y and Simmons C A 2011 (Micro)managing the mechanical microenvironment Integr. Biol. 3 959-71

[82] Jusoh N, Oh S, Kim S, Kim J and Jeon N L 2015 Microfluidic vascularized bone tissue model with hydroxyapatite-incorporated extracellular matrix Lab Chip 153984-8

[83] Birmingham E, Kreipke T C, Dolan E B, Coughlin T R, Owens P, McNamara L M, Niebur G $\mathrm{L}$ and McHugh P E 2015 Mechanical stimulation of bone marrow in situ induces bone formation in trabecular explants Ann. Biomed. Eng. 43 1036-50

[84] Kurth F, Eyer K, Franco-Obregón A and Dittrich P S 2012 A new mechanobiological era: Microfluidic pathways to apply and sense forces at the cellular level Curr. Opin. Chem. Biol. 16 400-8

[85] Kou S, Pan L, van Noort D, Meng G, Wu X, Sun H, Xu J and Lee I 2011 A multishear microfluidic device for quantitative analysis of calcium dynamics in osteoblasts Biochem. Biophys. Res. Commun. 408 350-5

[86] Roy B, Das T, Mishra D, Maiti T K and Chakraborty S 2014 Oscillatory shear stress induced calcium flickers in osteoblast cells Integr. Biol. 6289

[87] Malone A M D, et al. 2007 The role of actin cytoskeleton in oscillatory fluid flow-induced signaling in MC3T3-E1 osteoblasts. Am. J. Physiol. Cell Physiol. 292 C1830-6

[88] Altmann B, Löchner A, Swain M, Kohal R, Giselbrecht S, Gottwald E, Steinberg T and Tomakidi P 2014 Biomaterials differences in morphogenesis of 3D cultured primary human osteoblasts under static and micro fl uidic growth conditions Biomaterials 35 3208-19

[89] Park J Y, Yoo S J, Patel L, Lee S H and Lee S H 2010 Cell morphological response to low shear stress in a two-dimensional culture microsystem with magnitudes comparable to interstitial shear stress Biorheology 47 165-78

[90] Zheng W, Xie Y, Zhang W, Wang D, Ma W, Wang Z and Jiang X 2012 Fluid flow stress induced contraction and re-spread of mesenchymal stem cells: a microfluidic study Integr. Biol. 41102

[91] Yourek G, McCormick S M, Mao J J and Reilly G C 2010 Shear stress induces osteogenic differentiation of human mesenchymal stem cells Regen Med 5 713-24

[92] Kim K M, et al. 2014 Shear stress induced by an interstitial level of slow flow increases the osteogenic differentiation of mesenchymal stem cells through TAZ activation PLoS One 9 e92427

[93] Jang K, Sato K, Igawa K, Chung U Il and Kitamori T 2008 Development of an osteoblastbased 3D continuous-perfusion microfluidic system for drug screening Anal. Bioanal. Chem. $390825-32$

[94] Yu W, Qu H, Hu G, Zhang Q, Song K, Guan H, Liu T and Qin J 2014 A microfluidic-based 
multi-shear device for investigating the effects of low fluid-induced stresses on osteoblasts PLoS One 9 1-7

[95] Riehl B D, Lee J S, Ha L, Kwon I K and Lim J Y 2017 Flowtaxis of osteoblast migration under fluid shear and the effect of RhoA kinase silencing PLoS One 12 1-16

[96] Jeon J H and Jeong O C 2012 Methodology for investigating the duration of intracellular calcium expression in response to mechanical stimulation in a single cell Microelectron. Eng. 98 642-6

[97] Sim W Y, Park S W, Park S H, Min B H, Park S R and Yang S S 2007 A pneumatic micro cell chip for the differentiation of human mesenchymal stem cells under mechanical stimulation Lab Chip 71775

[98] Song S H, Choi J and Jung H Il 2010 A microfluidic magnetic bead impact generator for physical stimulation of osteoblast cell Electrophoresis 31 2762-70

[99] McCoy R J and O'Brien F J 2010 Influence of shear stress in perfusion bioreactor cultures for the development of three-dimensional bone tissue constructs: a review Tissue Eng. Part B Rev. 16 587-601

[100] Beebe D J, Mensing G A and Walker G M 2002 Physics and applications of microfluidics in biology Annu. Rev. Biomed. Eng. 4 261-86

[101] Kirchhof K, Andar A, Yin H B, Gadegaard N, Riehle M O and Groth T 2011 Polyelectrolyte multilayers generated in a microfluidic device with $\mathrm{pH}$ gradients direct adhesion and movement of cells Lab Chip 113326

[102] Zhang Y, Gazit Z, Pelled G, Gazit D and Vunjak-Novakovic G 2011 Patterning osteogenesis by inducible gene expression in microfluidic culture systems Integr. Biol. 3 39-47

[103] Schliwa M 1982 Action of cytochalasin D on cytoskeletal networks J. Biol. Chem. 79-91

[104] Barata D, Spennati G, Correia C, Ribeiro N, Harink B, van Blitterswijk C, Habibovic P and van Rijt S 2017 Development of a shear stress-free microfluidic gradient generator capable of quantitatively analyzing single-cell morphology Biomed. Microdevices 19 1-10

[105] Harink B, Le Gac S, Barata D, van Blitterswijk C and Habibovic P 2015 Microfluidic platform with four orthogonal and overlapping gradients for soluble compound screening in regenerative medicine research Electrophoresis 36 475-84

[106] Wei C W, Cheng J Y and Young T H 2006 Elucidating in vitro cell-cell interaction using a microfluidic coculture system Biomed. Microdevices 8 65-71

[107] Liu C, Cui X, Ackermann T M, Flamini V, Chen W and Castillo A B 2016 Osteoblast-derived paracrine factors regulate angiogenesis in response to mechanical stimulation Integr. Biol. 8 785-94

[108] Neto E, et al. 2014 Sensory neurons and osteoblasts: close partners in a microfluidic platform Integr. Biol. 6 586-95

[109] Peng X Y L, Li L Q and Hong H S 2009 A vast-range speed control microchip for retention of all cell types. Lab Chip $93012-5$

[110] Perez R A, Choi S J, Han C M, Kim J J, Shim H, Leong K W and Kim H W 2016 Biomaterials control of pluripotent stem cell fate for regenerative therapy Prog. Mater. Sci. 82 234-93

[111] Martino S, D’Angelo F, Armentano I, Kenny J M and Orlacchio A 2012 Stem cell-biomaterial interactions for regenerative medicine Biotechnol. Adv. 30 338-51

[112] Toh Y-C, et al. 2007 A novel 3D mammalian cell perfusion-culture system in microfluidic channels Lab Chip 7 302-9

[113] Stamp M, Jötten A, Kudella P, Breyer D, Strobl F, Geislinger T, Wixforth A and Westerhausen C 2016 Exploring the limits of cell adhesion under shear stress within physiological conditions and beyond on a chip Diagnostics 638

[114] Hartmann A, et al. 2014 A novel tool for dynamic cell adhesion studies - the De-Adhesion Number Investigator DANI Lab Chip 14 542-6

[115] Barata D, Provaggi E, Van Blitterswijk C and Habibovic P 2017 Development of a microfluidic platform integrating high-resolution microstructured biomaterials to study cellmaterial interactions Lab Chip 17 4134-47 
[116] Abeille F, et al. 2014 Continuous microcarrier-based cell culture in a benchtop microfluidic bioreactor Lab Chip 143510

[117] Gu Y, Zhang W, Sun Q, Hao Y, Zilberberg J and Lee W Y 2015 Microbead-guided reconstruction of the 3D osteocyte network during microfluidic perfusion culture $J$. Mater. Chem. B 3 3625-33

[118] Moraes C, Wang G H, Sun Y and Simmons C A 2010 A microfabricated platform for highthroughput unconfined compression of micropatterned biomaterial arrays Biomaterials 31 57784

[119] Cheng C M, Steward R L and LeDuc P R 2009 Probing cell structure by controlling the mechanical environment with cell-substrate interactions J. Biomech. 42 187-92

[120] Burdick J A, Khademhosseini A and Langer R 2004 Fabrication of gradient hydrogels using a microfluidics/ photopolymerization process Langmuir 20 8-11

[121] Liu Z, Xiao L, Xu B, Zhang Y, Mak A F T, Li Y, Man W Y and Yang M2012 Covalently immobilized biomolecule gradient on hydrogel surface using a gradient generating microfluidic device for a quantitative mesenchymal stem cell study Biomicrofluidics $\mathbf{6} 02411$

[122] Zhou B, Gao X, Wang C, Ye Z, Gao Y, Xie J, Wu X and Wen W 2015 Functionalized PDMS with versatile and scalable surface roughness gradients for cell culture ACS Appl. Mater. Interfaces 7 17181-7

[123] Pagano G, Ventre M, Iannone M, Greco F, Maffettone P L and Netti P/A 2014 Optimizing design and fabrication of microfluidic devices for cell cultures: An effective approach to control cell microenvironment in three dimensions Biomicrofluidics 8046503

[124] Shi X, Zhou J, Zhao Y, Li L and Wu H 2013 Gradient-regulated hydrogel for interface tissue engineering: Steering simultaneous osteo/chondrogenesis of stem cells on a chip Adv. Healthc. Mater. 2 846-53

[125] Lee J H, Wang H, Kaplan J B and Lee W Y 2010 Effects of Staphylococcus epidermidis on osteoblast cell adhesion and viability on a Ti alloy surface in a microfluidic co-culture environment Acta Biomater. 6 4422-9

[126] Lee J H, Gu Y, Wang H and Lee W Y 2012 Microfluidic 3D bone tissue model for highthroughput evaluation of wound-healing and infection-preventing biomaterials Biomaterials $\mathbf{3 3}$ 999-1006

[127] Bruce A, Evans R, Mezan R, Shi L, Moses B S, Martin K H, Gibson L F and Yang Y 2015 Three-dimensional microfluidic tri-culture model of the bone marrow microenvironment for study of acute lymphoblastic leukemia PLoS One 10 1-16

[128] Giridharan V, Yun Y, Hajdu P, Conforti L, Collins B, Jang Y and Sankar J 2012 Microfluidic platforms for evaluation of nanobiomaterials: A review J. Nanomater. 2012789841

[129] Ramdongbang A, Kunhorm P, Kuntanawat P, Laksanasopin T and Sirivisoot S 2017 Increased osteoblast growth with graphene oxide in a microwell-based biochip BMEiCON 2016 - 9th Biomedical Engineering International Conference (Laung Prabang: IEEE)

[130] Ingber D E 2016 Reverse Engineering Human Pathophysiology with Organs-on-Chips Cell $1641105-9$ 